\title{
4.3 Designing, manufacturing and researching of the heat accumulator work for pre-starting preparation of the car engine
}

\section{Using the heat accumulators in various departments. Problems of using the heat accumulators in transport.}

Heat accumulation followed by its use has been the subject of many studies in recent years. To accumulate heat developed devices - heat accumulators (HA). Heat accumulation with its subsequent use is the topic of many studies in recent years. To accumulate heat, heat accumulators (HA) have been developed [266-268]. The work of the heat accumulator is carried out due to the absorption (during melting) and release (during crystallization) of heat as a result of heating and cooling of the working fluid - a material with a phase transition, or heat-accumulating material (HAM). Crystalline hydrates of inorganic salt and bases or organic compounds based on kinds of paraffin are the most often used as heat accumulator actuating fluid [269, 270]. Phase transition heat accumulators are used in the construction industry, where they are used in wall panels [271]; in agriculture for heating greenhouses at night [267, 272]; in ventilation systems to maintain a comfortable temperature during the day [270]; for heating system and hot water supply systems [270]; for some technological processes, such as drying [272]. The heat-accumulating material melts and thus absorbs heat in the warm period of the day (for example, from the sun) and gives it away at night during crystallization, which is accompanied by the release of heat.

In transport equipment, thermal batteries of the phase transition are used to solve the problem of quick engine starting and heating the interior of the vehicle in the cold season [273-275].

The question is that at low ambient temperatures during a layover of a car, for example, at night, there are difficulties with the engine start at the beginning of operation (so-called "cold start"). It takes a long time for the engine to warm up, with the car's engine idling, consuming a significant amount of fuel, releasing exhaust gases into the atmosphere, and keeping the car's interior cold for a long time, creating discomfort for the driver and passengers. 
Cold start is characterized by decreasing engine life, increasing in specific fuel consumption, difficulty in ensuring the starting speed of the crankshaft, deterioration of the conditions of mixture formation, and ignition of the combustible mixture. It is caused by decreasing in the temperature of motor oil, fuel, the storage battery, details of the engine, and features of its starting properties.

One of the solutions to minimize the negative effects of cold start is pre-start thermal preparation of the engine [275]. The specified preparation is realized using preheaters which depending on the principle of work are subdivided into electric $(220 \mathrm{~V}$ and $12 \mathrm{~V}$ ), independent, executed in the form of the separate petrol or diesel module, and the thermal accumulators representing devices for accumulation of the released parasitic heat during the engine work in the form of heated fluid in the cooling circuit or the thermal energy of the exhaust gases.

When choosing a heat source between the exhaust gases and the engine coolant it should be noted that the engine exhaust gases have a temperature of $600-700{ }^{\circ} \mathrm{C}$, which has a negative impact on HAM, the metal of HA structure, and overheating (boiling) of the engine coolant. In addition, providing the heat accumulator with exhaust gases requires engine operation, so when a layover of a car for a long time, to melt HAM you need to use other heat sources. Therefore, we consider a more promising use as a heat transfer fluid for HA engine coolant.

In addition to the heat of the phase transition, the heat of heating of the solid and liquid phases is used. The advantage of such structures is the high thermal capacitance, which determines the compactness of the structure. In addition, the constancy of their discharging temperature provides greater efficiency than the temperature of the declining storage systems with heated coolant.

Thus, the most acceptable from a practical point of view for transport equipment is to use heat accumulators based on the phase transition solid-liquid (fusible heataccumulating materials) [276-279].

There is not enough research in this area. There are a limited number of design solutions of phase transition heat accumulators for the prelaunch procedure of internal combustion engines. The specific of such a heat accumulator work is not taken into 
account, which is that unlike other industries (e.g. construction, heating systems, drying process), where the whole HAM mass is constantly in contact with the substance to which HAM gives its heat, in our case the engine coolant is in both of the HA and the cooling cladding and is mixed immediately before the engine start, while its temperature decreases. This feature requires a slightly different approach to creating conditions for the stable operation of the entire system. The lack of data on temperature changes of HAM, coolant liquid, and engine over time at different stages of HA use does not allow to give recommendations on the HAM mass required to ensure quick engine starting, HA charging time, and in the charged state.

From the perspective of the above, the purpose of the work is to develop a methodology for designing a heat accumulator for pre-starting the car engine, based on obtained by modeling data from the manufacture of experimental setups and production prototype and research work of HA.

\section{Designs of phase transition heat accumulator for cars}

We offer the following options as constructive solutions of phase transition HA: encapsulated; shell and tube, lamellar, screw, and also with scraper removal of HAM, with removal HAM by ultrasound; with direct contact and pumping HAM; with evaporative-convective heat transfer [280-282].

The most common are heat accumulators with HAM in capsules or the intertube space. This ensures the rational use of the internal volume of the heat accumulator and applies traditional technology for the manufacture of heat exchangers. Each of these types of devices has its advantages. Capsule type HA is not only highly reliable and efficient but also allows you to create a heat transfer surface that can balance for the consumption of phase transitions. Heat accumulators - shell-and-tube heat exchangers are characterized by resistance to water hammer, reduced requirements for the purity of the environment, the relative ease of manufacture. The engine coolant moves in the tubular space of the device, and in the intertube space, there is a heat-accumulating material. 


\section{Stages of heat accumulator design for pre-starting preparation of the car engine}

The design of shell-and-tube heat storage equipment involves several stages (steps). At the first stage, we carried out the orientation of the thermal load on the device, taking into account the expected operating conditions, thermal parameters of the engine's working process, and thermal capacity indicators of materials. At this stage, it is possible to conduct design studies in CFD systems to clarify the heat balance, fluid flow regimes and resistance in the system channels, to assess the uneven heating of the cylinders [283].

At the second stage, we selected the constructional design and layout of the apparatus with the detailed prediction of the fluid flow regimes in the intertube space, the choice of the configuration of the arrangement of tubes or capsules with a heataccumulating substance, the calculation of heat losses, hydraulic resistance of sections, etc. Calculations at this stage are also conveniently performed in CFD systems, with a multivariate choice from a variety of possible CAD layouts.

At the next stage, we carried out a calculated analysis of the dynamics of engine heating elements for the selected heat storage material (often there is a lack of the necessary passport parameters of the material from the supplier, in connection with the additional laboratory studies thet may be required). The calculations are performed based on averaged numerical schemes, the input parameters for which are the data of the first stage (or full-scale characteristics). At this stage, it is possible to predict the dynamics of not only the working process but also modeling the accumulation phase and the standstill phase.

At the last stage, we created a bench model with conducting full-scale proofing.

We consider stages of designing the heat accumulator in more detail and concerning the heat accumulator for preparation for starting the car engine.

\section{The first stage is the orientation of the thermal load on the device.}

This step is because we determine the efficiency of the preheater by the speed and uniformity of heating of the car engine. When designing or selecting preheaters, it 
is necessary to take into account the distinctives of the circulating fluid heat exchange in the cooling circuit with the engine and the outer surface of the cylinder block and the cylinder head with the environment. Excessive power of the tubular heater leads to local overheating of the liquid in the area close to the heater, and, as a consequence, the decomposition of the liquid, which reduces its service life. In addition, overheating the heater also adversely affects its operating life. Therefore, the power of the heater must be consistent with the speed of the liquid inside the circuit.

This preliminary agreement can be made by calculation studies of hydrodynamics and heat transfer for the main types of engines to determine the uneven heating of the cylinder block and cylinder head, the required warm-up time by supplying heated fluid to the engine with a temperature that will ensure sufficient system efficiency for the environment. This unevenness will be significantly influenced by several factors, including the geometry of the internal channels and the conditions of fluid circulation in the shell, the state of the inner surface of the channels, the properties of the circulating fluid and its consumption, the dimensions of engine elements and their thermophysical parameters, ambient temperature and heat transfer from the engine surface for the relevant season. The approximate solution of such a problem using, for example, the average heat capacity and engine mass, average hydraulic and thermal resistance, etc. [284] allows us to consider the process only at a qualitative level. In this paper, we conducted a numerical simulation of the flow with heat transfer in the channels of the engine shell. We used computer fluid dynamics (CFD) methods for this purpose. The list of tasks to be solved by CFD methods is constantly expanding. There is a constant renewal of models, in particular, models of turbulence, improving numerical calculation methods, increasing the productivity of computer technology. The vast majority of CFD software products use methods based on solving Navier-Stokes equations to describe turbulent flows.

As applied to a stationary process, the equations consist, as always, of the equations of continuity and motion (1,2 - summation over repeated indices is performed): 


$$
\begin{gathered}
\frac{\partial u_{i}}{\partial x_{i}}=0 \\
\frac{\partial}{\partial x_{j}}\left(u_{i} u_{j}\right)=-\frac{1}{\rho} \frac{\partial}{\partial x_{i}} p^{*}+\frac{\partial}{\partial x_{j}}\left(v_{e} \tau_{i j}\right)+f_{i}, \\
p^{*}=p+\frac{2}{3} \rho k, \tau_{i j}=\frac{\partial u_{i}}{\partial x_{j}}+\frac{\partial u_{j}}{\partial x_{i}}, v_{e}=v+v_{t}
\end{gathered}
$$

where

$k$ - specific kinetic energy of turbulence, $\mathrm{m}^{2} / \mathrm{s}^{2}, v-$ kinematic viscosity coefficient of the liquid, $\mathrm{m}^{2} / \mathrm{s}, v_{t}$ - turbulent viscosity, $\mathrm{m}^{2} / \mathrm{s}, p-$ the averaged pressure, $\mathrm{Pa}, u_{i}$-averaged components of the velocity vector in the Cartesian coordinate system, $\mathrm{m} / \mathrm{s}, f_{i}-$ vector of mass forces, $\mathrm{m} / \mathrm{s}^{2}$.

To close $(1,2)$ a two-parameter $k-\varepsilon$ turbulence model has recently become widespread due to the good coincidence of the obtained numerical results with the experimental data, as well as the significant rate of convergence of the basic algorithm. In this model, the turbulence parameters are calculated from the equations:

$$
\begin{gathered}
\frac{\partial}{\partial x_{j}}\left(k u_{j}-v_{k} \frac{\partial k}{\partial x_{j}}\right)=H_{k} \\
\frac{\partial}{\partial x_{j}}\left(\varepsilon u_{j}-v_{\varepsilon} \frac{\partial \varepsilon}{\partial x_{j}}\right)=H_{\varepsilon} \\
v_{t}=C_{\mu} \frac{k^{2}}{\varepsilon},
\end{gathered}
$$

where $\varepsilon$ - turbulent energy dissipation rate, $\mathrm{m}^{2} / \mathrm{s}^{3}$,

$$
\begin{gathered}
H_{k}=G-\varepsilon, H_{\varepsilon}=C_{\varepsilon 1}^{*} \frac{\varepsilon}{k} G-C_{\varepsilon 2} \frac{\varepsilon^{2}}{k}, G=v_{t} \tau_{i j} \frac{\partial u_{i}}{\partial x_{j}}, C_{\varepsilon 1}^{*}=C_{\varepsilon 1}-\eta \frac{1-\eta / \eta_{0}}{1+\beta \eta^{3}}, \\
\eta=\sqrt{\frac{G}{C_{\mu} \varepsilon}}, \\
v_{k}=v+\frac{v_{t}}{\sigma_{k}}, v_{\varepsilon}=v+\frac{v_{t}}{\sigma_{\varepsilon}} .
\end{gathered}
$$

The empirical constants in the reduced equations are equal: 


$$
C_{\mu}=0.0845, C_{\varepsilon 1}=1.42, C_{\varepsilon 2}=1.68, \sigma_{k}=\sigma_{\varepsilon}=0.72, \eta_{0}=4.38, \beta=0.015 .
$$

It is known that such a model gives acceptable results for areas with developed turbulence, thus when $v_{t}>>v$. Of course, this is not done near a solid wall. In this regard, empirically derived laws of fluid behavior are additionally set in the form of wall functions to determine the parameters of turbulence near the wall. This issue is considered in detail in the works [284].

The calculated study was performed using the package CFX-5.7 [285]. The calculation area with the calculation grid is presented in Fig. 1, $a$. The design area consisted of 4 sub-areas: the area adjacent to the cylinder block (solid), the area of the cylinder head (solid), the flow zone in the cylinder block (fluid), the flow zone in the cylinder head (fluid). We performed construction of the calculation grid using the CFX-Mesh module. The calculated grid numbered 3 million elements (Fig. 1), grid independence was verified by performing calculations for one of the modes on denser and more sparse grids, taking into account the control over the required values of the parameter $\mathrm{y}+$ on the wall [285].

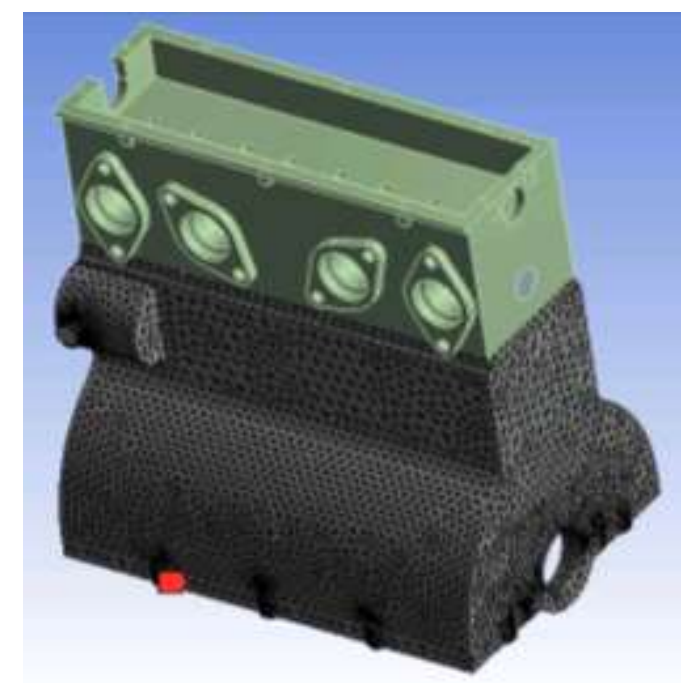

a)

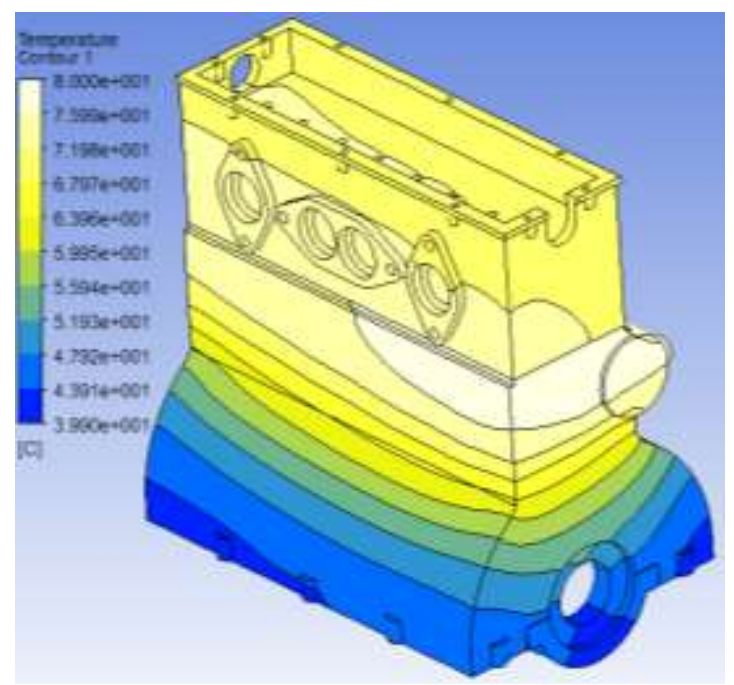

b)

Figure 1. Computational grid $(a)$ and the picture of heating the outer surfaces of the engine $(b)$. 
In all cases, the flow rate was set at the inlet, which corresponds to the available field data with a temperature of $80{ }^{\circ} \mathrm{C}$, at the outlet - static pressure. We set the condition Conservative Interface Flux for solid-liquid interfaces, General Connection for the liquid-liquid interface, and heat transfer for external walls of solid domains. The average heat transfer coefficient $\alpha$ for natural convection according to [286] was calculated from the equation:

$$
N u=0.75(\mathrm{Gr} \cdot \mathrm{Pr})^{0.25},
$$

where $N u=\alpha L / \lambda-$ Nusselt criterion, $G r=g \beta\left(\bar{t}_{c}-t_{o}\right) L / v^{2}-$ Grashof number, $L-$ characteristic wall size for the task (engine height), $m, \lambda$ - thermal conductivity of air, $\mathrm{W} /(\mathrm{m} \cdot \mathrm{K}) ; \mathrm{g}$ - free-fall acceleration, $\mathrm{m} / \mathrm{s}^{2} ; \quad \beta$ - coefficient of volumetric expansion of the environment, $\mathrm{K}^{-1} ; v$ - kinematic viscosity of air, $\mathrm{m}^{2} / \mathrm{s} ; \Delta t=\bar{t}_{\mathrm{c}}-t_{\mathrm{o}}-$ temperature pressure, ${ }^{\circ} \mathrm{C}, t_{\mathrm{o}}=0{ }^{\circ} \mathrm{C}-$ model ambient temperature. Consecutive calculations of heat transfer were defined as $\alpha \approx 10 \mathrm{~W} /\left(\mathrm{m}^{2} \cdot \mathrm{K}\right)$.

We performed current calculations in a stationary setting. At a low cost, the convergence of calculations was complicated, which requires a detailed comparison with experimental data. As a result of calculations, we received the warming up picture of engine blocks (Fig. 1, $b$ ), according to which there is noticeable uneven heating of the cylinders in the unit on one side (Fig. 2, $a, b$ ), however, a sufficient temperature that provides a comfortable start in the area of the cylinder head for a given state of the environment on the other. 


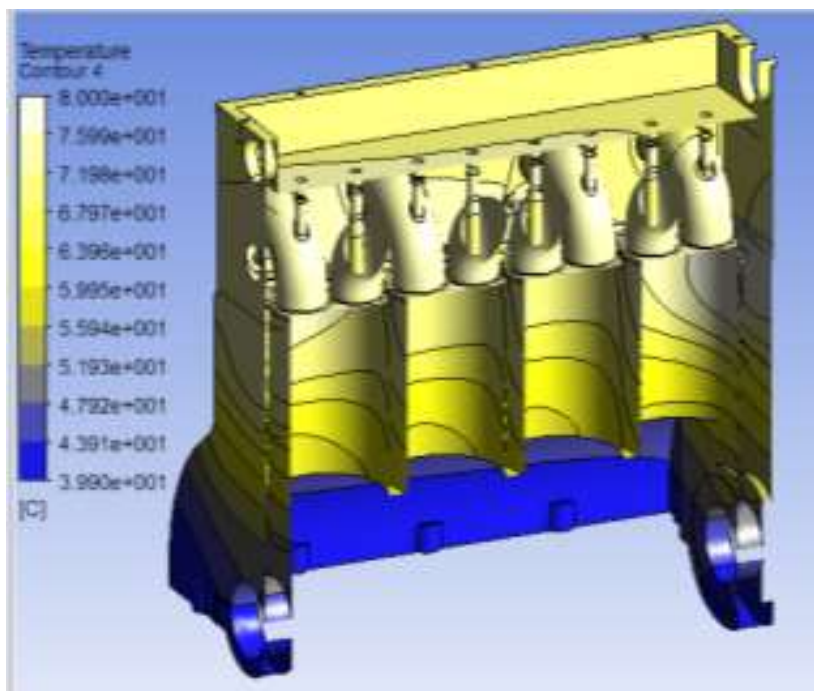

a)
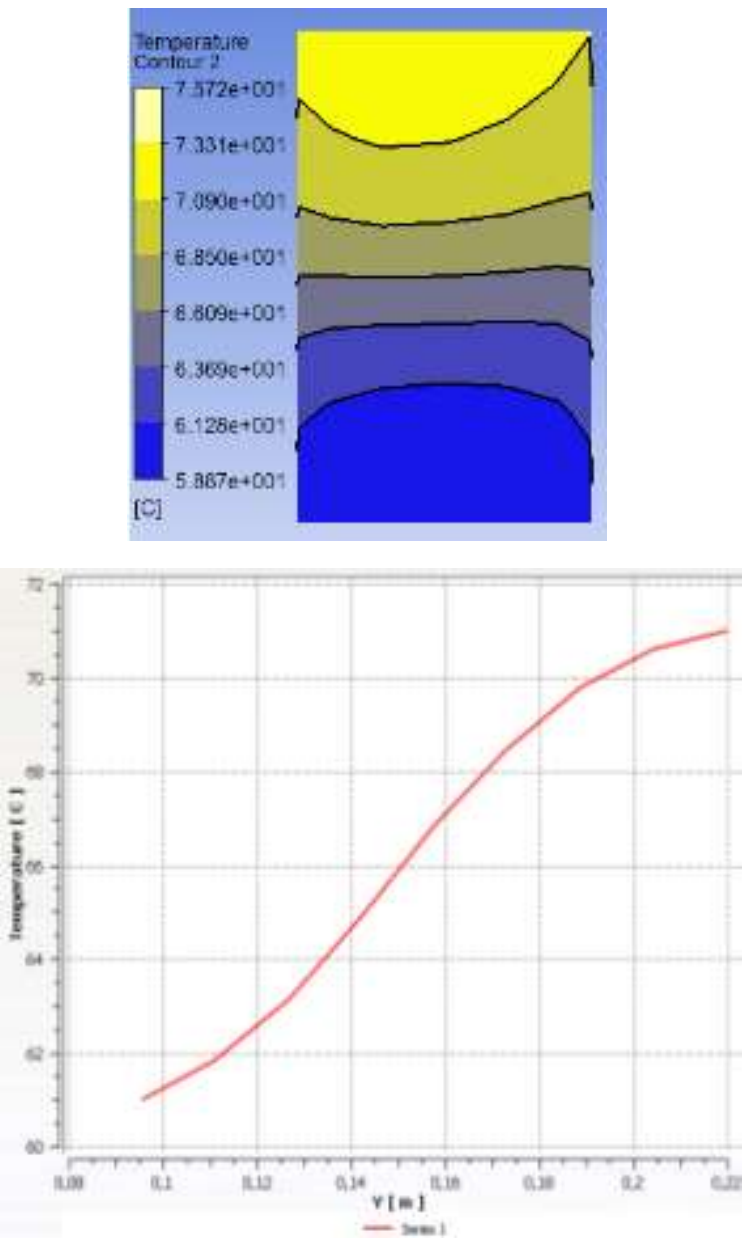

b)

Figure 2. Warming up of internal surfaces of the engine $(a)$ and a picture of warming up of a surface of the cylinder $(b)$.

The significant uneven flow of fluid through the engine channels and a complex hydrodynamic picture in general with the presence of a large number of stagnant zones (Fig. 3, a, b). It should be noted, in addition, that this picture can vary greatly depending on the performance of the channels in the engine shell and the specific model of the engine as a whole.

Thus, the implementation of the first stage of design guides on the heat load on the device, and, in addition, makes it possible to obtain a picture of the warming of the engine units and to conclude on the sufficiency of temperature to ensure a comfortable start of the engine. 


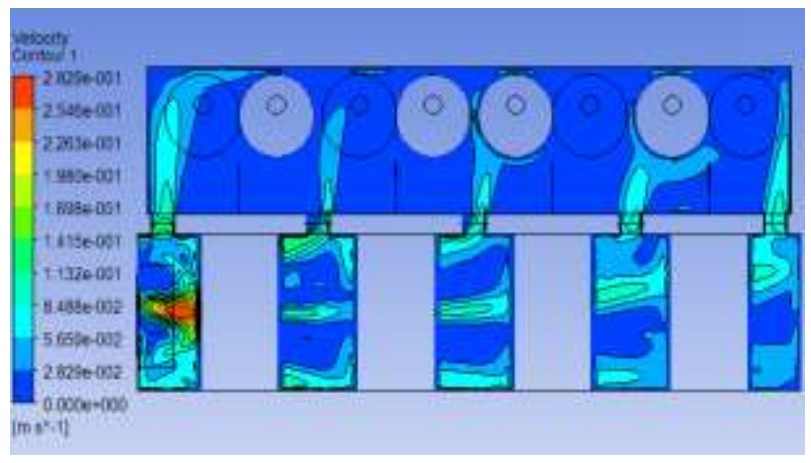

a)

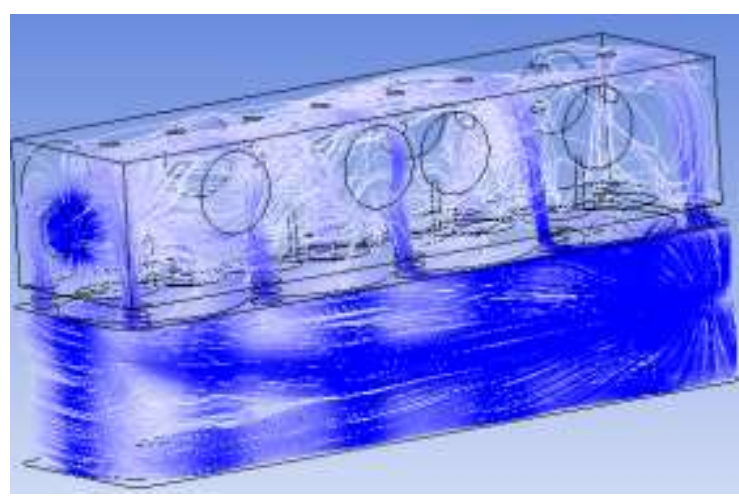

b)

Figure 3. Distribution of velocities in the longitudinal section $(a)$ and the flow line $(b)$.

The second stage is the choice of structural design and layout design of the device.

Capsule and shell-and-tube types of constructive execution of the heat accumulator are considered as the most acceptable in work. We consider examples of arrangement of such heat accumulators on three options of constructive execution.

Capsule HA (option 1) represents capacity on which the heat carrier circulates and in which capsules with heat-accumulating material are fixed.

We chose a seamless aluminum tube with an outer diameter of $22 \mathrm{~mm}$ and a wall thickness of $1.25 \mathrm{~mm}$ as blanks for the capsules. The selected diameter seems to us to be the most optimal, as it allows us to obtain a sufficient surface area of the coolant contact with the capsules while maintaining an acceptable complexity of manufacture. The capsules were filled with molten heat-accumulating material - barium hydroxide octahydrate $\left(\mathrm{T}_{\mathrm{mol}}=78^{\circ} \mathrm{C}\right)$. At the same time, there was free space on top to compensate for thermal expansion. We carried out sealing of the capsules by pipe flaring on a lathe after pressing into it pre-made steel plugs. The plugs are provided with shaped grooves filled with high-temperature sealant (Fig. 4). 


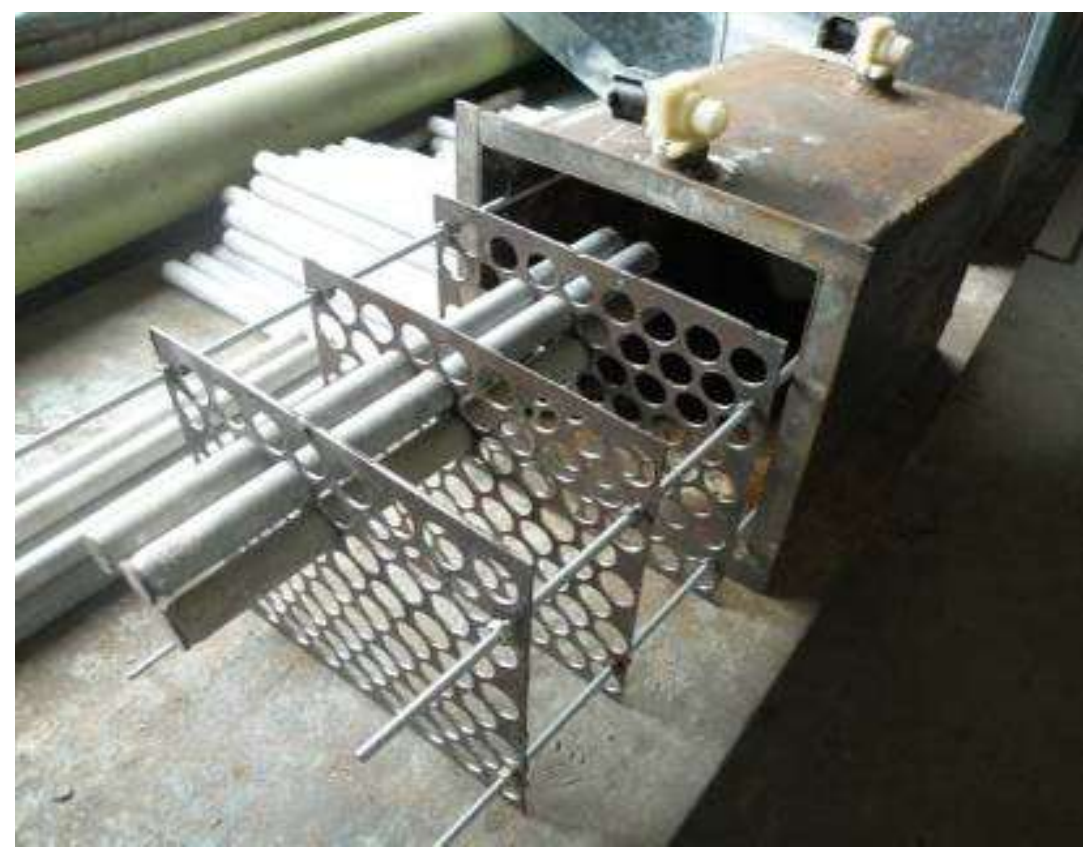

Figure 4. The first design option of the experimental sample - with capsules of heat-accumulating substance.

Liquid flow is formed in the internal volume by the mutual arrangement of the capsules with the heat-accumulating material, thanks to which it is possible to minimize hydraulic losses and improve the heat exchange between the heat carrier and the heat-accumulating substance contained in the flasks.

Fig. 5 shows the structural design of the HA indirect storage (option 2) in the form of a shell-and-tube heat exchanger with a shell. The volume is constant, the circulation is forced by a water pump. Casing - all-metal cylinder with flanges. Heat carrying agent - fluid from the engine cooling system, enters the casing through threaded pipes on the side cover with built-in solenoid valves (the normally closed type with a supply voltage of $12 \mathrm{~V}$, included in the general electrical network of the car in parallel with the electric circulating pump) to prevent convective heat exchange with the engine cooling system during idle time. Heat-accumulating material fills the tubes located throughout the space of the casing and absorbs thermal energy. The main advantage of this design is the simplicity of manufacture and operation, as well as significant cheapness. This design also eliminates uneven heating HAM and allows us to make covers and flanges as light as possible. This heat accumulator is powerful, able to reach operating parameters in a short period. The disadvantages include: 
- the possibility of premature crystallization due to uneven heating, which leads to faster discharge;

- increased dimensions and weight due to the complex system of pipelines, material thickness, bolted fasteners, etc.;

- difficulties in thermal insulation;

- the complexity of cleaning the intertube space;

- corrosion problems in places of tubes flaring with HAM.

All these disadvantages listed above negatively affect the possibility of installation on a modern car, but it is possible to install it on trucks and buses.

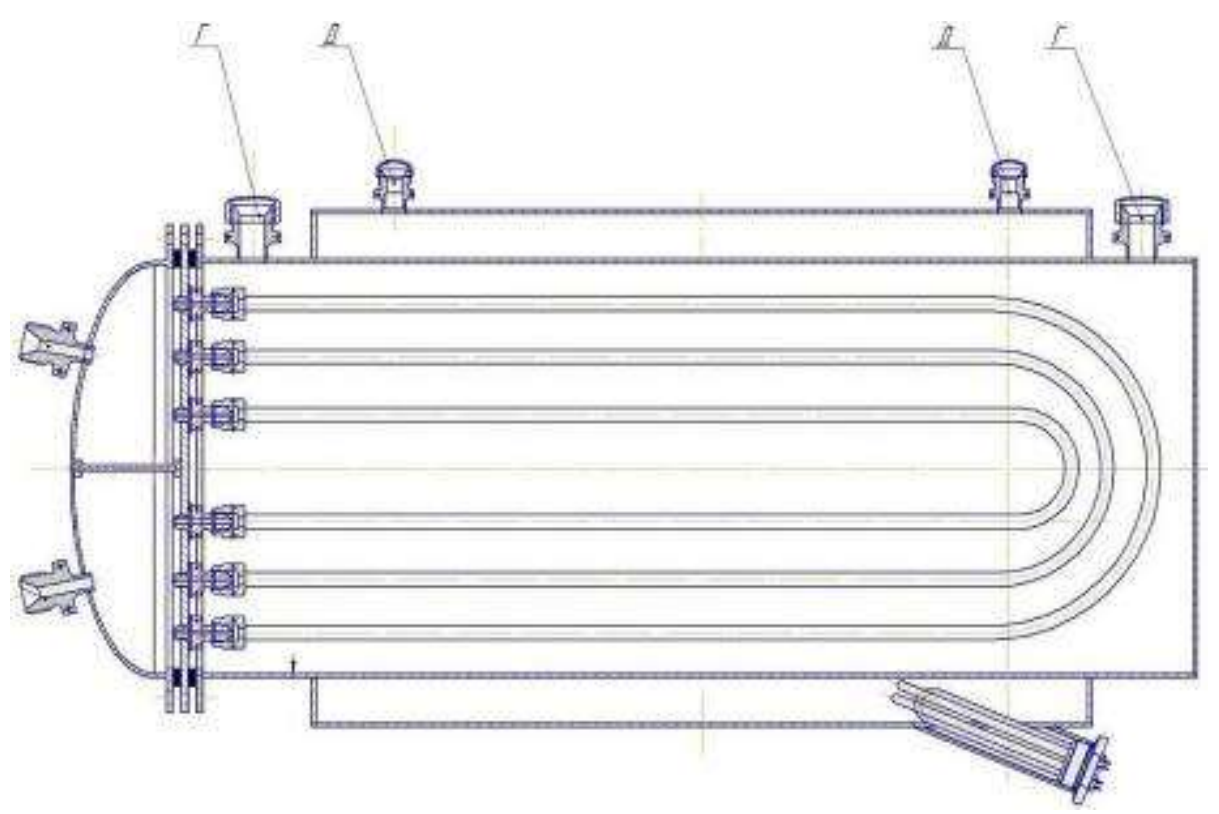

Figure 5. The second design option of the heat accumulator in the form of a shelland-tube heat exchanger.

Heat-accumulating substance - crystal hydrates or paraffins (waxes).

The design of option 3 (Fig. 6) is similar to option 2, but to eliminate all the shortcomings of the previous design, we made the following changes: we reduced the size of the entire system by almost 1.5 times, which allowed to install this system on a much larger number of cars; welds, flanges - have been replaced by bolted joints; we changed the installation of the tubular heating element (THE) to horizontal; the heatstoring material was replaced by ozokerite; to improve heat transfer to ozokerite, copper wire was evenly decomposed around the tubes. 


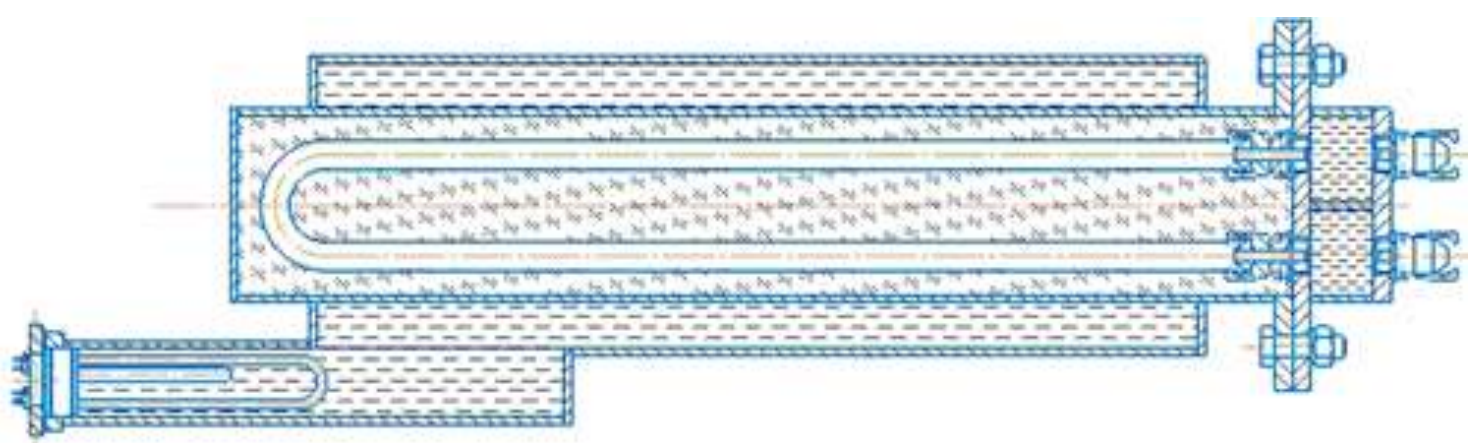

Figure 6. The third option of the heat accumulator design.

\section{Constructive optimization}

Detailed forecasting of fluid flow regimes in the intertube space and heat flows makes it possible to choose the configuration of the location of tubes or capsules with heat-accumulating substance, calculate heat loss and hydraulic support sections, etc. We consider the above example of the capsule design of the heat accumulator.

We designed and manufactured steel partitions for the spatial orientation of the capsules inside the casing. They are fastened together with threaded pins and sealed against the walls of the heat accumulator housing. This design allows you to divide the internal volume of the heat accumulator into compartments and increase several times the path traversed by the liquid when passing inside the device with high heat capture in one pass. The mutual placement of the capsules inside the heat accumulator creates a labyrinthine flow of coolant, which allows you to evenly heat the heat accumulating substance in the capsules, as well as intensify the heat transfer process by increasing the speed of the coolant that washes them. At the same time it is necessary to try to place in the set volume the maximum volume of heat-accumulating material.

We developed several options of the mutual arrangement of the capsules inside the casing. From them the two most acceptable options which became object of modeling are chosen.

Option 1 involves the checkerboard arrangement of the capsules along the flow of liquid cooling (Fig. 7). 


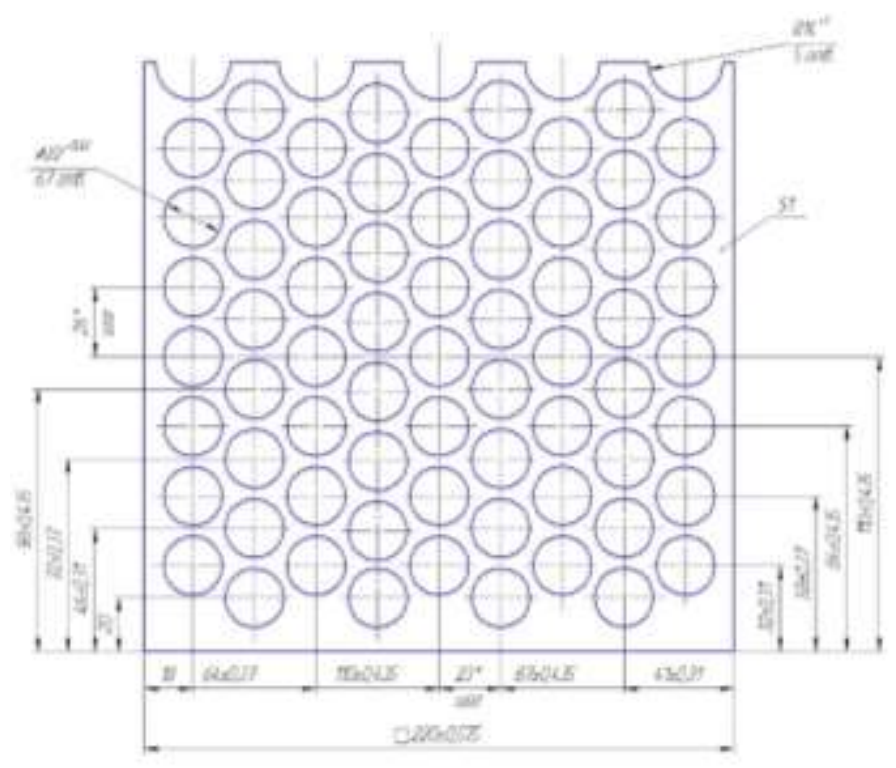

a)

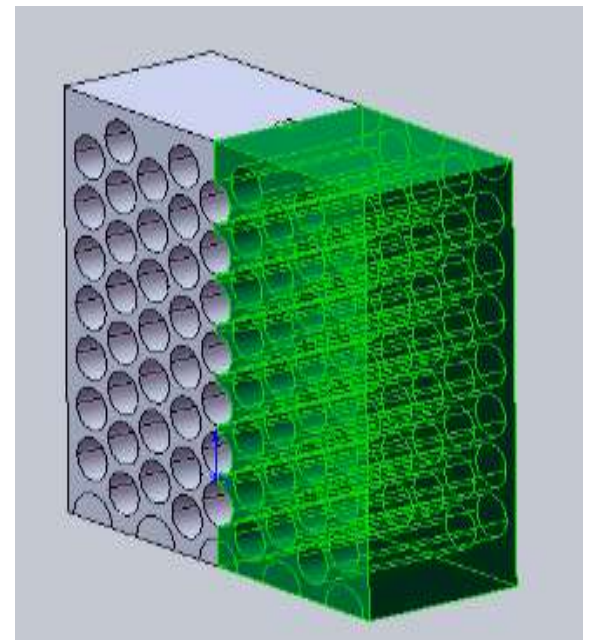

b)

Figure 7. Option structural design of the heat accumulator:

a) - working drawing of the partition; $b$ ) - spatial model of one section.

We carried out the modeling of hydrodynamic and thermal processes taking place inside the heat accumulator. Calculations at this stage are convenient to perform in CFD-systems, with a variety of choices from many possible CAD-layouts. Fig.8 presented the finite element model of one section, taking into account the symmetry and the scheme of fluid supply.

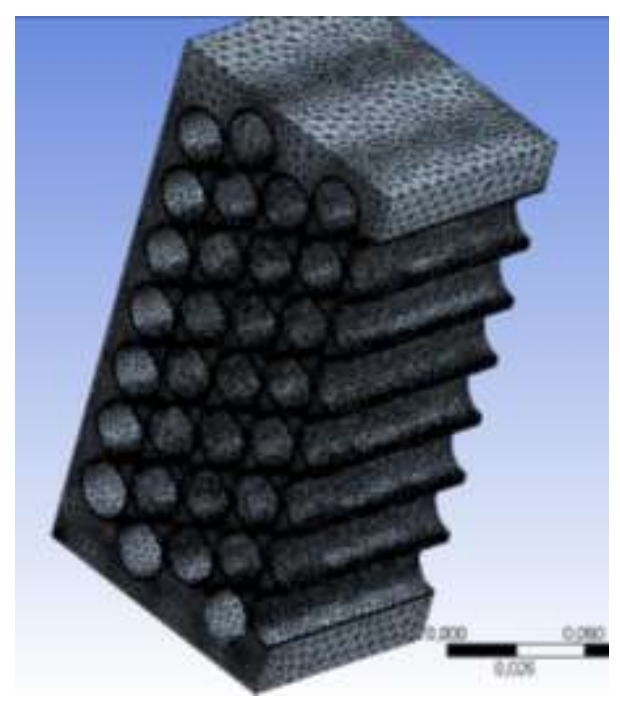

a)

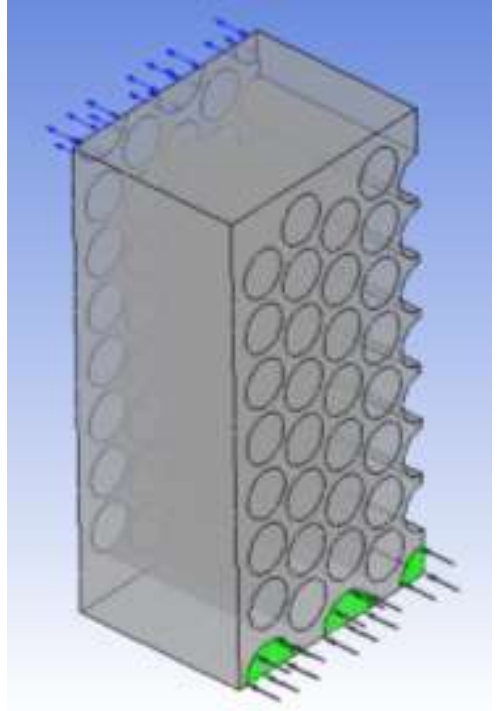

b)

Figure 8. Finite element model of one section (a) taking into account the symmetry and the scheme of fluid supply. 
In this option, the liquid moves in the vertical direction through virtually rectilinear channels formed by the space between the capsules (Fig. 9). This arrangement is characterized by low hydraulic resistance and a high fluid flow rate. This has a positive effect on the performance of the electric circulation pump but leads to uneven distribution of coolant flows within the volume of the heat accumulator. In fig. 9 arrow shows the undesirable increased flow along the wall, which accounts for $30 \%$ of the total consumption.

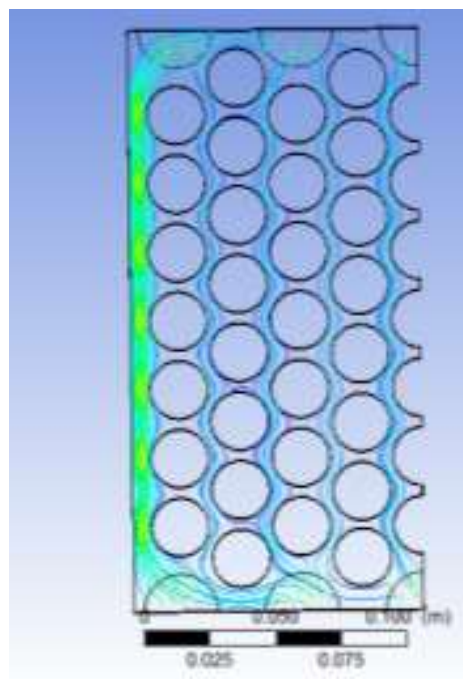

a)

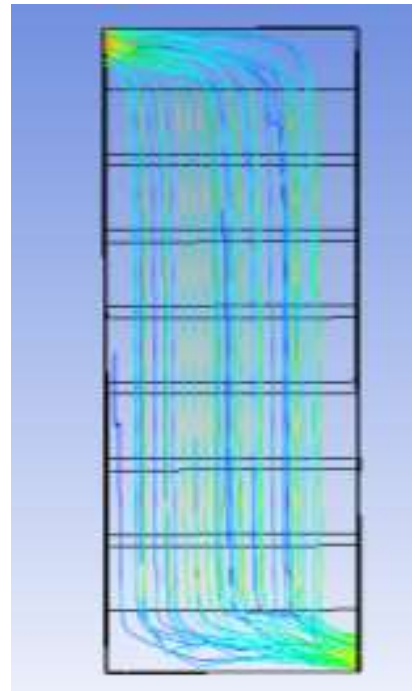

b)

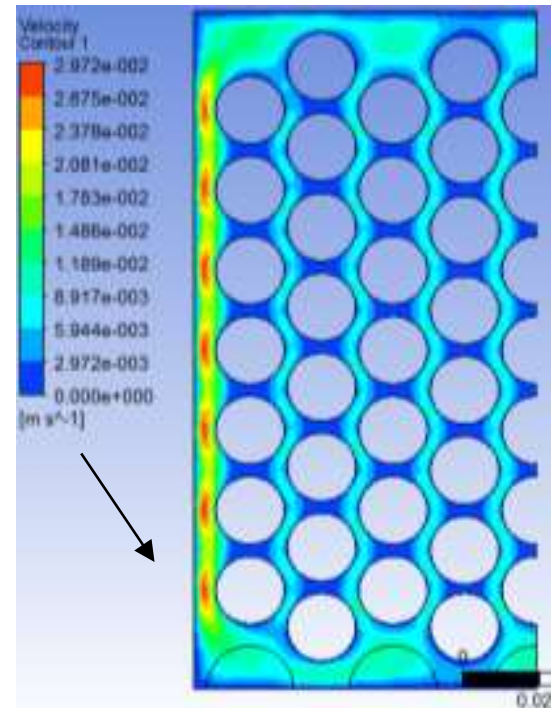

c)

Figure 9. The results of modeling the current line in the cross section $(a)$ and longitudinal section $(b)$ and the distribution of velocities in the cross section $(c)$.

The surface area may not be sufficient for efficient heat transfer. To reduce the effect of near-wall flow, it is advisable to close the supply through the extreme lumens in the septum (Fig. 10). However, this solution only partially solves the problem. The total pressure drop is $320 \mathrm{~Pa}$. 


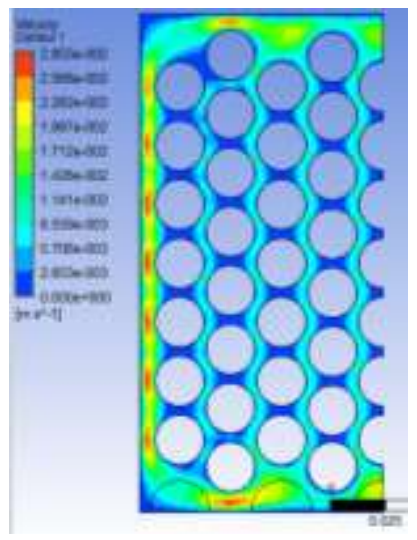

a)

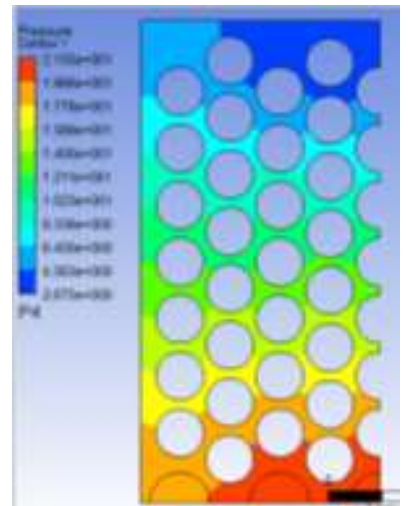

b)

Figure 10. The results of modeling the distribution of velocities $(a)$ and pressure $(b)$ in the cross section when feeding only through the central lumens.

As a result, a laminar flow regime is observed in the entire volume of liquid at a given flow rate $(3 \mathrm{l} / \mathrm{min})$. We performed thermal calculation for a fully and evenly charged heat accumulator in the phase transition mode in all tubes (Fig. 11). The phase transition temperature was thus set on the surface of the tubes (it is assumed that the heat of the phase transition is consumed over a period of time longer than the time of the liquid particle in the sections; in this case the phase transition temperature is $78^{\circ} \mathrm{C}$ ). Ambient temperature $-10{ }^{\circ} \mathrm{C}$. Thermal insulation of the casing of the heat accumulator - expanded polystyrene $\left(\mathrm{K}=0.8 \mathrm{~W} / \mathrm{m}^{2} \mathrm{~K}\right)$ on all perimeter $50 \mathrm{~mm}$ thick. The liquid (tosol cooling agent) is fed at a temperature of $0{ }^{\circ} \mathrm{C}$ (antifreeze parameters are taken for the worst conditions - viscosity and density correspond to a temperature of $0{ }^{\circ} \mathrm{C}$ ).

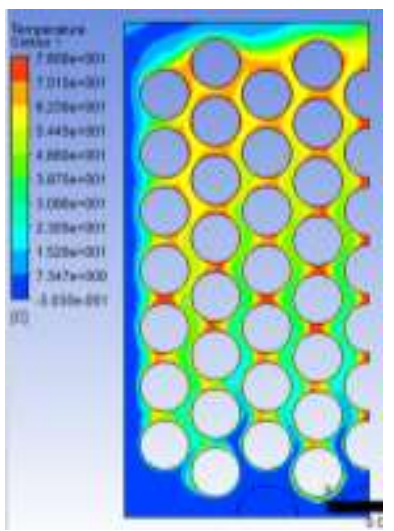

a)

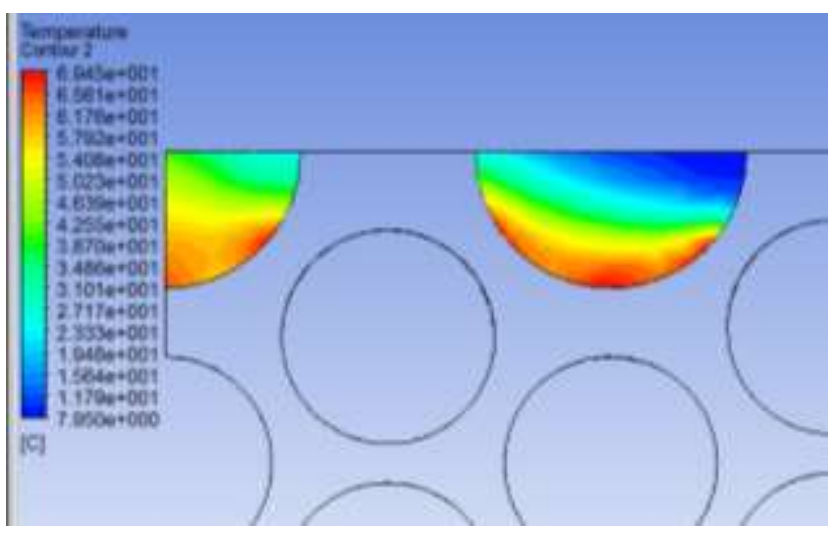

b)

Figure 11. Temperature field in the cross section $(a)$ and at the exit $(b)$. 
Thus, at a tube temperature of $78{ }^{\circ} \mathrm{C}$ (phase transition for barium hydroxide octahydrate), ambient temperature $-10{ }^{\circ} \mathrm{C}$, tosol cooling agent temperature at the inlet to the section $0{ }^{\circ} \mathrm{C}$ and the specified insulation temperature of the coolant at the outlet of the heat accumulator averaged $40{ }^{\circ} \mathrm{C}$. Along the entire wall, the negative impact of the wall-flow is noticeable - the liquid with low temperature reaches the outlets. Thus, to get rid of unwanted near-wall flow and flow equalization in general, a simple overlap of the extreme inlets in the partition is not enough.

To solve the problem, option 2 is considered, which assumes a checkerboard arrangement of tubes across the flow (Fig. 12). We modeled the section completely due to the lack of a vertical plane of symmetry, which can be attributed to the disadvantages of this arrangement, as there will be thermal asymmetry.

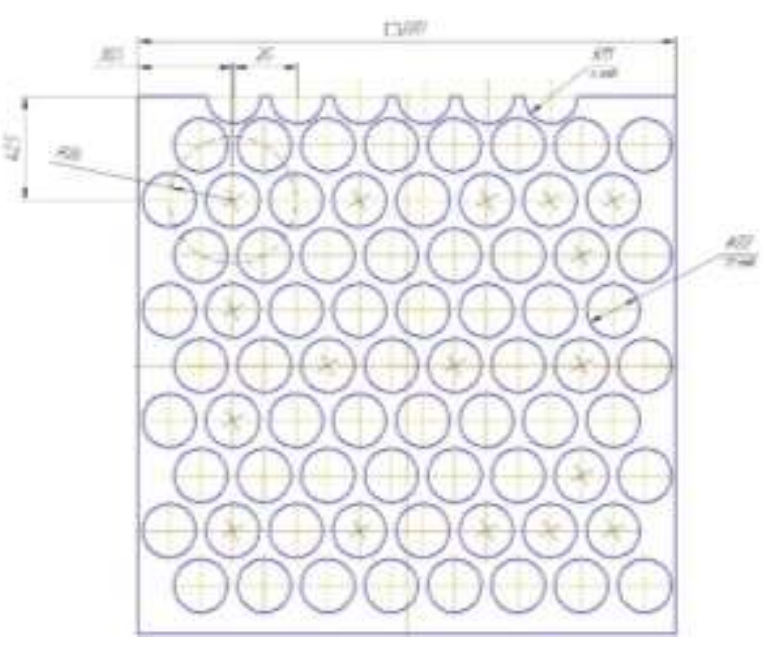

a)

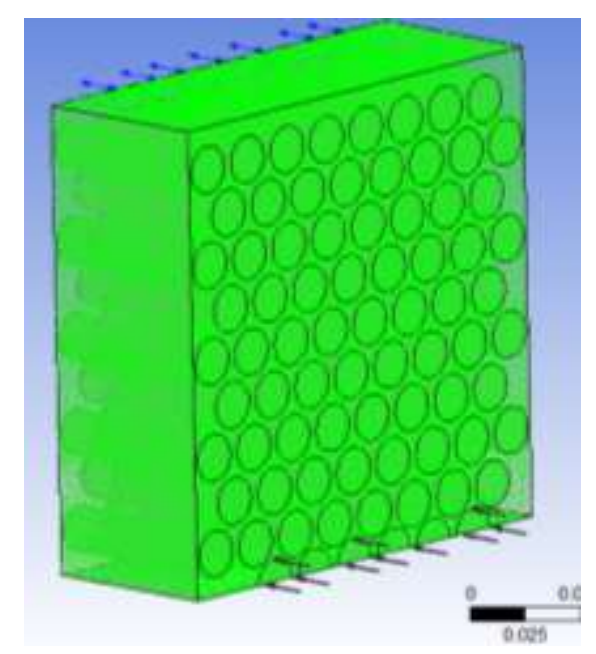

b)

Figure 12. The design of the development model:

a) - working drawing of the partition; $b$ ) - finite element model of the tubule section.

At such arrangement more uniform distribution of a stream in section and absence of a near-wall stream in comparison with option 1 (Fig. 13) is appreciable. The total pressure drop is $300 \mathrm{~Pa}$. 


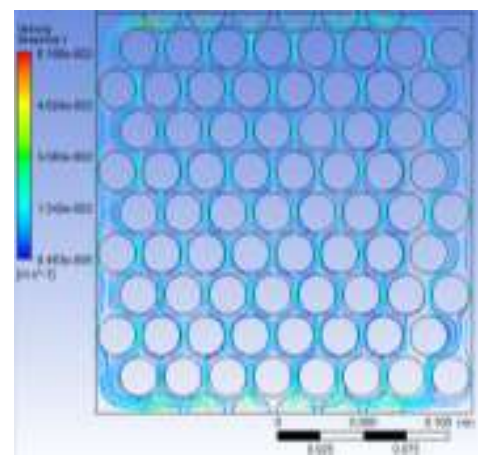

a)

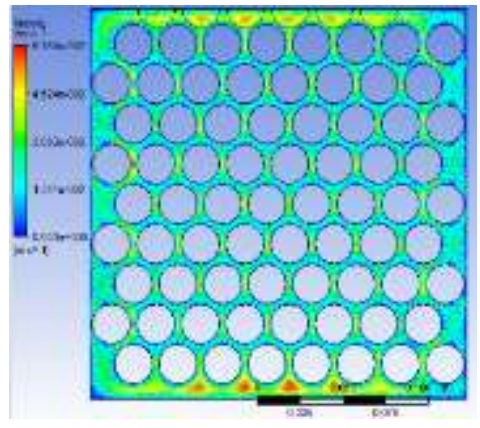

b)

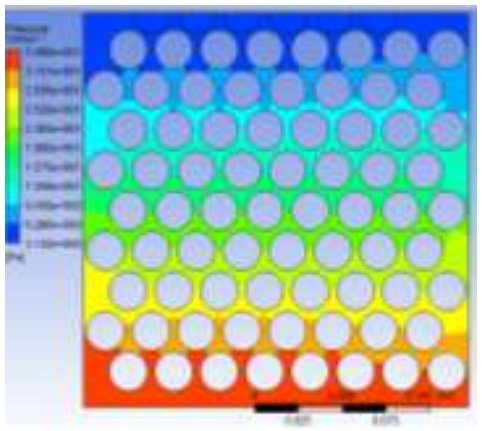

c)

Figure 13. Flow lines $(a)$, distribution of velocities $(b)$ and pressures $(c)$ in cross section.

In addition, this arrangement is characterized by the absence of speed differences with a slight decrease in pressure drop. The result is more favorable conditions for heat transfer - no stagnant zones, more uniform temperature distribution across the crosssection (Fig. 14).

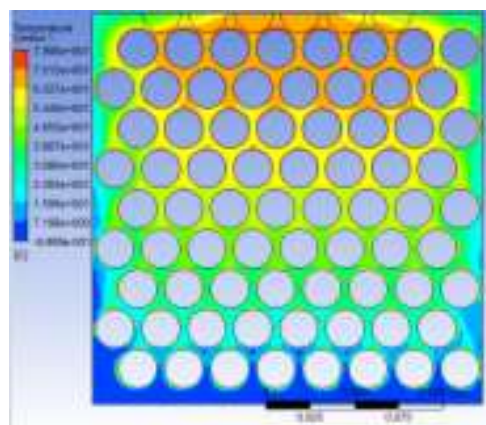

a)

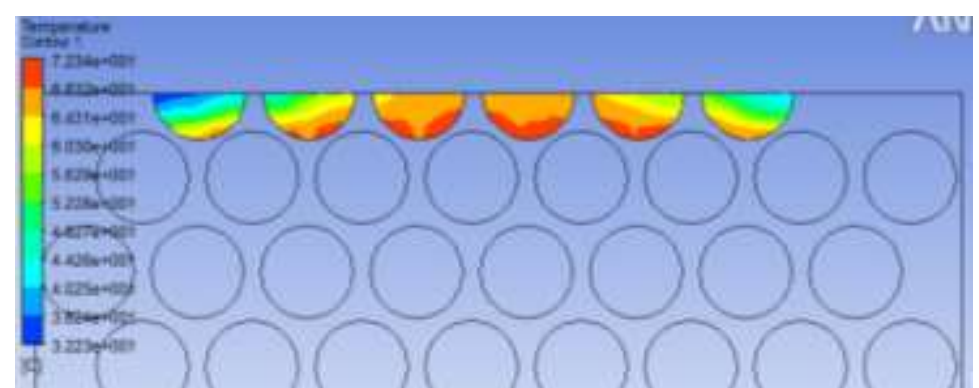

b)

Figure 14. Temperature field in the section $(a)$ and at the exit from it $(b)$.

The input simulation parameters (properties of substances and cost characteristics) fully correspond to the previous scheme. As a result, at a tube temperature of $78{ }^{\circ} \mathrm{C}$ (phase transition of barium hydroxide octahydrate), ambient temperature $-10{ }^{\circ} \mathrm{C}$, tosol cooling agent temperature at the inlet to the section $0{ }^{\circ} \mathrm{C}$ and appropriate insulation, the increase in outlet temperature averages $60{ }^{\circ} \mathrm{C}$. Thus, more heat is removed from the tubes in one pass, which corresponds to the heat transfer found in the section. However, there is a slight temperature asymmetry.

Further intensification of the heat transfer process is possible due to the use of material for the manufacture of capsules with a higher coefficient of thermal 
conductivity, as well as the creation of finning on their outer surface, which further turbulent flow.

Thus, preliminary CFD modeling of thermal preparation processes of internal combustion engines allows optimizing the design parameters of the equipment, to choose the appropriate solutions from many possible layouts, to calculate energy consumption at an early stage of design. This approach can be extended to individual calculations to determine the optimal layout of heat storage devices for a wide range of automotive equipment.

\section{The third stage is to conduct calculated studies of the dynamics of warming up}

\section{the engine elements.}

To determine the warm-up time of the engine with a heat accumulator requires detailed coordination of the hydrodynamic problem in the channels of the engine and heat transfer with the phase transition in the heat accumulator, which requires careful preparation of the heat accumulator model.

As is known, the Stefan condition is usually used on the basis of the heat balance for the phase separation surface [287]:

$$
\rho_{s o l} q_{n} \frac{\partial s_{n}}{\partial \tau}=\left.\lambda_{\text {liq }} \frac{\partial T}{\partial n}\right|_{n \rightarrow+0}-\left.\lambda_{\text {sol }} \frac{\partial T}{\partial n}\right|_{n \rightarrow-0},
$$

where $s_{n}$ - the displacement of the phase boundary in the normal direction $n, \tau$ - time, $T$ - the temperature, $q_{n}$-the latent heat of fusion, $\lambda_{l i q} \mathrm{i} \lambda_{\text {sol }}$-are the thermal conductivity coefficients of the liquid and solid phases, respectively.

In addition to this condition, the vast majority of Stefan-type problems use the condition of constant temperature at the interfacial boundary. However, in some cases, the simulation of the melting-freezing process of the working fluid is desirable to use the method of effective heat capacity [288] without explicit allocation of the position of the phase transition boundaries, with the calculation of convective heat transfer in the melt:

$$
c_{e f} \rho\left(\frac{\partial T}{\partial \tau}+\mathbf{v} \nabla T\right)=\nabla\left(\lambda_{e f} \nabla T\right)+q,
$$


where $c_{e f}, \lambda_{e f}-$ effective values of heat capacity and thermal conductivity which take into account the heat of fusion in the Stefan's task [288], and the presence of convective heat transfer, $\mathbf{v}$ - velocity field (convective currents), $q$ - power of internal heat sources, if they belong. To take into account the phase transition, the effective heat capacity includes a delta function and is represented as

$$
c_{e f}=c(T)+q_{n} \delta\left(T-T^{*}\right),
$$

where $\mathrm{T}^{*}-$ is the phase transition temperature.

In the numerical implementation in the finite temperature range $\Delta t$ for the phase transition point, the second term can be replaced by the expression $q_{n} / \Delta T$.

Some heat-accumulating substances are materials with strongly blurred boundaries of phase transformations solid-liquid. In these cases, the temperature interval of phase transformations can stretch by several degrees, so the temperature dependence of the specific heat $c=c(T)$ is used which in the phase transition have one or more peaks (Fig. 15), and the phase transition region is not a surface, it is a sphere [289]. It is also possible the presence of supercooling during crystallization which for example is characteristic of crystal hydrates without forming solid particles of additives [290] but in practice the account of this phenomenon is rarely performed.

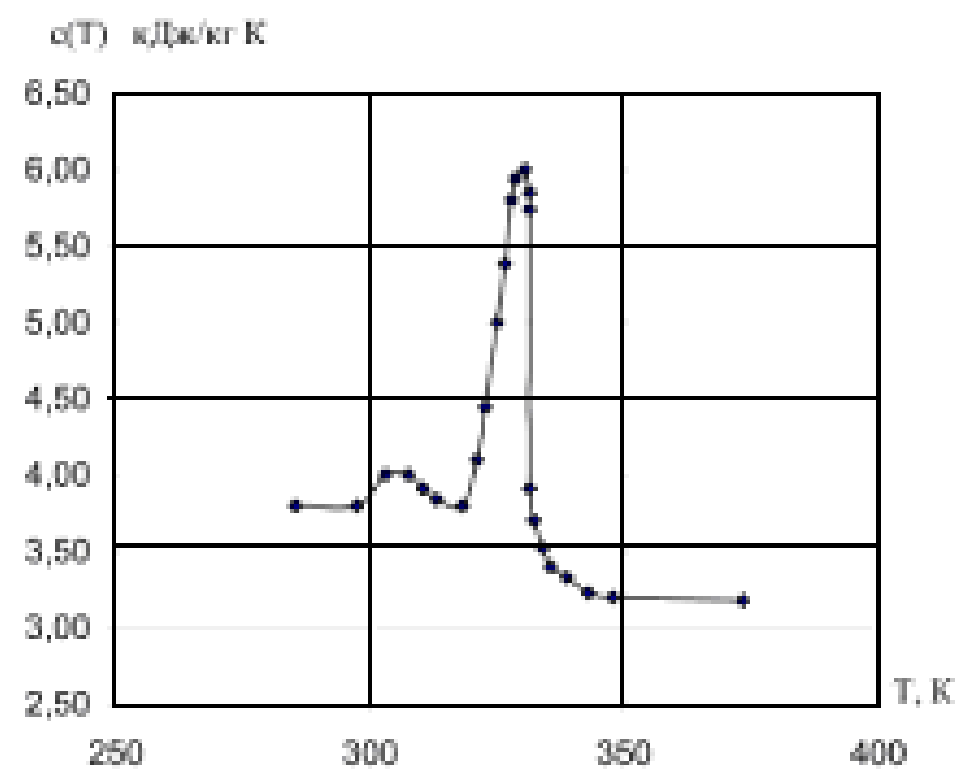

Figure 15 . Heat capacity curve according to the method of effective heat capacity. 
We performed numerical calculations of the system engine-circulating fluidheat storage material-environment in two stages. In the first stage, the parameters of thermal resistance in the engine system and piping system (Fig. 16) for different coolant temperatures were calculated by the finite-volume method in the CFD system. In the second stage the problem was numerically solved by the method of equivalent thermal circuits [291].

We perform this division of the task into stages to reduce the need for computational resources. The complete finite-volume model of the system requires the significant computing capacity, and therefore it is advisable to perform calculations of the complete system in the relevant CFD programs at the final stage.

The system of equations of thermal state for each section has the form:

$$
\begin{aligned}
& C_{1} \frac{d T_{1}}{d \tau}+\Lambda_{11}\left(T_{1}-T_{2}\right)+\Lambda_{12}\left(T_{1}-T_{3}\right)+\Lambda_{13}\left(T_{1}-T_{e t}\right)=P_{1}, \\
& C_{2} \frac{d T_{2}}{d \tau}+\Lambda_{21}\left(T_{1}-T_{2}\right)+\Lambda_{22}\left(T_{1}-T_{3}\right)+\Lambda_{23}\left(T_{1}-T_{e t}\right)=P_{2}, \\
& \ldots,
\end{aligned}
$$

or in matrix form:

$$
[C] \cdot \dot{\mathbf{T}}+[\Lambda] \cdot \mathbf{T}=\mathbf{P},
$$

where $[C]-$ the matrix of heat capacities (diagonal), $\mathbf{T}-$ is the temperature column of the nodes, $T_{e t}-$ the environment temperature, $[\Lambda]-$ the matrix of thermal conductivities, and $\mathbf{P}$ - the power vector of heat sources. The heat capacity corresponding to the heat accumulating substance is given by the piecewise function in accordance with the method of effective heat capacity.

From this perspective, the system of equations of thermal state for each section has the form: 


$$
\begin{aligned}
& m_{1} c_{1} \frac{d T_{1}}{d t}=-k_{12}\left(T_{1}-T_{2}\right) F_{12}-k_{10}\left(T_{1}-T_{e .}\right) F_{13}, \\
& m_{2} c_{2} \frac{d T_{2}}{d t}=-k_{12}\left(T_{2}-T_{1}\right) F_{12}-k_{20}\left(T_{2}-T_{e}\right) F_{20}-k_{23}\left(T_{2}-T_{3}\right) F_{23}, \\
& m_{3} c_{3} \frac{d T_{3}}{d t}=-k_{23}\left(T_{3}-T_{2}\right) F_{23}-k_{30}\left(T_{3}-T_{e .}\right) F_{30},
\end{aligned}
$$

where $T_{1}, T_{2}, T_{3}$ - respectively the temperature (average of the volume in the system) of the heat storage material, engine coolant and engine;

$m_{1}$ - mass of heat storage material, $m_{2}$ - mass of cooling fluid involved in heat transfer (for different cycles is different), $\mathrm{m}_{3}$ - payload mass of the engine (involved in heat transfer);

$c_{1}, c_{2}, c_{3},-$ corresponding to the heat capacity, while $c_{1}$ is given by the method of effective heat capacity as a piecewise function in the form;

$-k_{12}\left(T_{1}-T_{2}\right) F_{12}$ - heat current from the material to the cooling fluid (and the corresponding heat transfer coefficient and surface area);

$-k_{10}\left(T_{1}-T_{e}\right) F_{10}-$ heat current from the material into the environment through the walls of the heat exchanger (and the corresponding heat transfer coefficient and surface area);

$-k_{20}\left(T_{2}-T_{e}\right) F_{20}-$ heat current from the material to the environment through the connecting pipes (and the corresponding heat transfer coefficient and surface area); $-k_{23}\left(T_{2}-T_{3}\right) F_{23}-$ heat current from the cooling fluid to the engine (and the corresponding heat transfer coefficient and surface area);

$-k_{30}\left(T_{3}-T_{e}\right) F_{30}-$ heat current from the engine to the environment through its surface.

Boundary conditions $\mathrm{T}_{1}\left({ }^{\circ} \mathrm{C}\right)$ - the temperature of the heat storage material after standing, $\mathrm{T}_{2}\left({ }^{\circ} \mathrm{C}\right)$ - initial temperature of cooling fluid (in calculations as average between the engine and material, but the arbitrary choice is also proportional to the ratio of volumes in the engine and in the heat exchanger), $\mathrm{T}_{3}\left({ }^{\circ} \mathrm{C}\right)-$ initial engine temperature (it takes as environment temperature). 
We performed the calculation for the engine model using Maple computer programs according to the following finite-difference scheme:

$$
\begin{aligned}
& T_{1, i+1}=T_{1, i}-\frac{1}{m_{1} c_{1}}\left[k_{12}\left(T_{1, i}-T_{2, i}\right) F_{12}+k_{10}\left(T_{1, i}-T_{e n v_{i}}\right) F_{13}\right] \Delta t, \\
& T_{2, i+1}=T_{2, i}-\frac{1}{m_{2} c_{2}}\left[k_{12}\left(T_{2, i}-T_{1, i}\right) F_{12}+k_{20}\left(T_{2, i}-T_{e n v_{i}}\right) F_{20}+k_{23}\left(T_{2, i}-T_{3, i}\right) F_{23}\right] \Delta t, \\
& T_{3, i+1}=T_{3, i}-\frac{1}{m_{3} c_{3}}\left[k_{23}\left(T_{3, i}-T_{2, i}\right) F_{23}+k_{30}\left(T_{3, i}-T_{e n v_{i}}\right) F_{30}\right] \Delta t,
\end{aligned}
$$

where $i$-iteration number by time.

Numerical calculations of engine warm-up by discharging the heat accumulator according to the above method for substances with blurred (kinds of paraffin, Fig. 16, a) and delta-like phase transition (Fig. 16, b) have characteristic areas of phase transition.

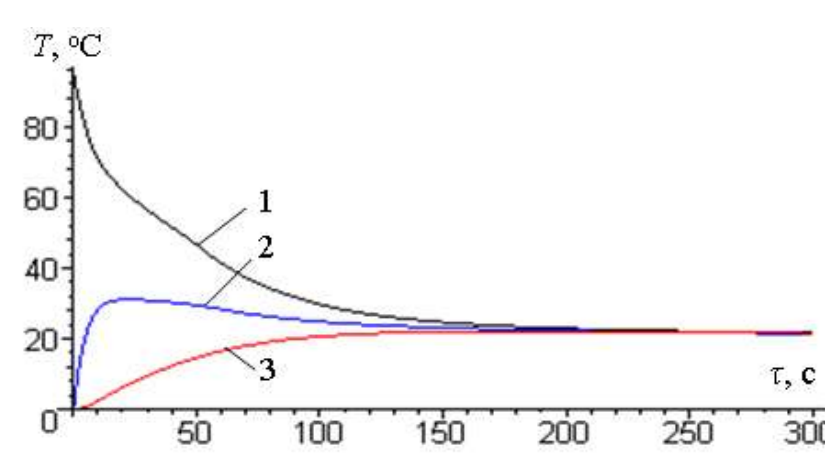

a)

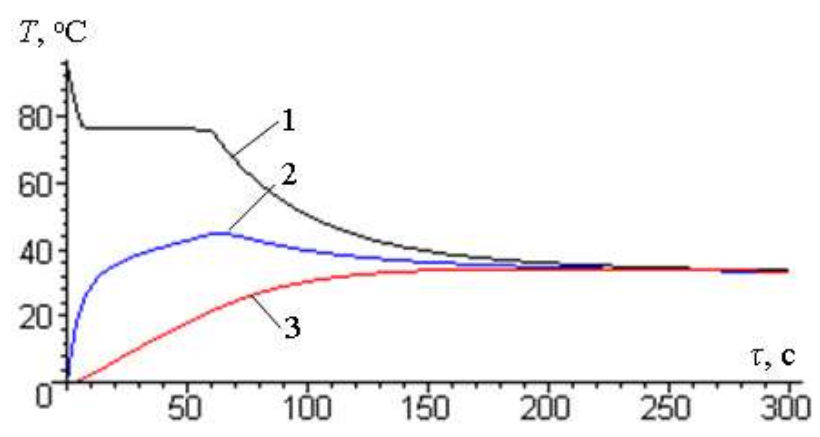

b)

Figure 16. The results of numerical calculations of engine warm-up by discharging the heat accumulator;

a) for substances with blurred (model substance - kinds of paraffin),

$b$ ) for substances with a delta-like phase transition (according to data for crystal hydrates).

1 - discharging of heat-accumulating substance, 2 - heating of coolant, 3 warming up of the engine.

The calculation of the warming dynamics of the engine elements allowed to determine the warm-up time of the engine with a heat accumulator, and the calculation results are in good agreement with experimental data, and the model can be used to select design parameters of heat accumulators. 
In fig. 17, $a-b$ presents the results of solving the system of equations (13) for a four-cylinder engine, heat accumulator, and circulation system using different design solutions TA in the second stage.

We performed the calculations under the conditions specified in the table. 1.

Table 1. Conditions for experiments

\begin{tabular}{|c|c|c|c|c|}
\hline \multirow{2}{*}{\multicolumn{2}{|c|}{ Parameters of HA elements }} & \multicolumn{3}{|c|}{ Option of HA } \\
\hline & & \multirow{2}{*}{$\frac{1}{35}$} & \multirow{2}{*}{$\frac{2}{10}$} & \multirow{2}{*}{$\frac{3}{1,3,6}$} \\
\hline Parameters & Number of tubes or capsules & & & \\
\hline capsules & Diameter of tubes (capsules), $\mathrm{m}$ & 0,02 & 0,02 & 0,015 \\
\hline (option 1) & Length of tubes or capsules (total), m & 1 & 1 & 1,1 \\
\hline $\begin{array}{l}\text { or tubes } \\
\text { (options } 2,3 \text { ) }\end{array}$ & $\begin{array}{l}\text { Thermal surface area of the material, } \\
\mathrm{m}^{2}\end{array}$ & 1,8 & 0,62 & 0,1554 \\
\hline \multirow[t]{3}{*}{ HA parameters } & Length of HA, m & 0,6 & 0,6 & 0,6 \\
\hline & Diameter TA, $\mathrm{m}$ & 0,1 & 0,1 & 0,1 \\
\hline & Heat accumulator cover area, $\mathrm{m}^{2}$ & 0,397 & 0,54 & 0,54 \\
\hline \multirow{5}{*}{$\begin{array}{l}\text { Volumes and masses } \\
\text { of HAM and cooling } \\
\text { fluid }\end{array}$} & Volume of HAM, $\mathrm{m}^{3}$ & 0,0182 & $25 \cdot 10^{-3}$ & 0,004127 \\
\hline & Weight of HAM, kg & 36,4 & 50 & 4,1227 \\
\hline & $\begin{array}{l}\text { Volume of tosol cooling agent in HA } \\
\text { tubes, } \mathrm{m}^{3}\end{array}$ & 0,000047 & 0,000583 & 0,000583 \\
\hline & Volume of circulating fluid in $\mathrm{HA}, \mathrm{m}^{3}$ & $11 \cdot 10^{3}$ & $11 \cdot 10^{3}$ & $11 \cdot 10^{3}$ \\
\hline & $\begin{array}{l}\text { Mass of circulating liquid in the heat } \\
\text { exchanger of devices, } \mathrm{kg}\end{array}$ & 11 & 3 & 28 \\
\hline \multirow{2}{*}{$\begin{array}{l}\text { Physical properties of } \\
\text { materials }\end{array}$} & Density of HAM, $\mathrm{kg} / \mathrm{m}^{3}$ & 2000 & 2000 & 1000 \\
\hline & Density of circulating fluid, $\mathrm{kg} / \mathrm{m}^{3}$ & 1000 & 1000 & 1000 \\
\hline \multirow{5}{*}{$\begin{array}{l}\text { Thermophysical } \\
\text { characteristics of } \\
\text { HAM } \\
\text { and the engine } \\
\text { coolant }\end{array}$} & $\begin{array}{l}\text { Heat capacity of HAM outside the } \\
\text { phase transition, } \mathrm{J} /(\mathrm{kg} \cdot \mathrm{K})\end{array}$ & 3000 & 3000 & 3340 \\
\hline & $\begin{array}{l}\text { Heat transfer from the material } \\
\text { during natural convection (idle } \\
\text { time), } \mathrm{W} /\left(\mathrm{m}^{2} \cdot \mathrm{K}\right)\end{array}$ & 20 & 20 & 1000 \\
\hline & $\begin{array}{l}\text { Heat capacity of circulating fluid, } \\
\mathrm{J} /(\mathrm{kg} \cdot \mathrm{K})\end{array}$ & 3000 & 3000 & 3000 \\
\hline & $\begin{array}{l}\text { Heat of phase transition of HAM, } \\
\mathrm{J} / \mathrm{kg}\end{array}$ & $260 \cdot 10^{3}$ & $140 \cdot 10^{3}$ & $140 \cdot 10^{3}$ \\
\hline & $\begin{array}{l}\text { Heat transfer coefficient through } \\
\text { insulation, } \mathrm{W} /\left(\mathrm{m}^{2} \cdot \mathrm{K}\right)\end{array}$ & 0,74 & 0,74 & 0,74 \\
\hline
\end{tabular}




\begin{tabular}{|c|c|c|c|c|}
\hline & $\begin{array}{l}\text { Heat transfer coefficient to the } \\
\text { environment, } \mathrm{W} /\left(\mathrm{m}^{2} \cdot \mathrm{K}\right)\end{array}$ & 10 & 10 & 10 \\
\hline & $\begin{array}{l}\text { Phase transition temperature of HAM, } \\
{ }^{\circ} \mathrm{C}\end{array}$ & 78 & 78 & \\
\hline \multirow[t]{7}{*}{ Engine parameters } & $\begin{array}{l}\text { The volume of circulating fluid in the } \\
\text { engine, } 1\end{array}$ & 28 & 18 & 28 \\
\hline & Engine surface area (external), $\mathrm{m}^{2}$ & 2,7 & 2,7 & 2,7 \\
\hline & Engine surface area (internal), $\mathrm{m}^{2}$ & 2.2 & 2.2 & 2.2 \\
\hline & $\begin{array}{l}\text { Weight of the engine (involved in } \\
\text { heat transfer), } \mathrm{kg}\end{array}$ & 640 & 170 & 250 \\
\hline & $\begin{array}{l}\text { Average heat capacity of the engine, } \\
\mathrm{J} /(\mathrm{kg} \cdot \mathrm{K})\end{array}$ & 550 & 550 & 550 \\
\hline & $\begin{array}{l}\text { The thickness of the insulation layer } \\
\text { (foam), mm }\end{array}$ & 50 & 50 & 50 \\
\hline & Ambient temperature, ${ }^{\circ} \mathrm{C}$ & -20 & -10 & -10 \\
\hline
\end{tabular}

\section{For option 1}
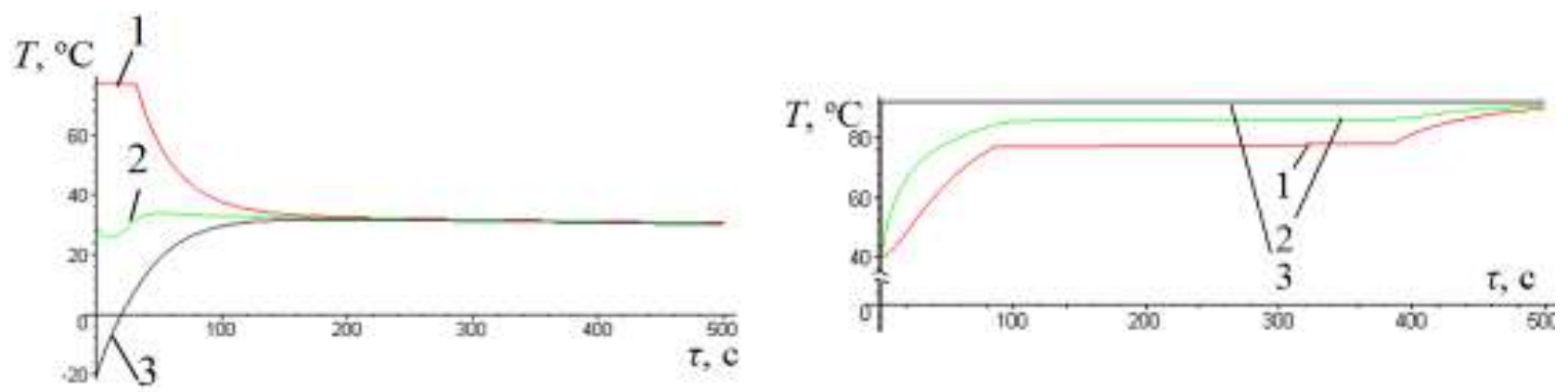

a)

b)

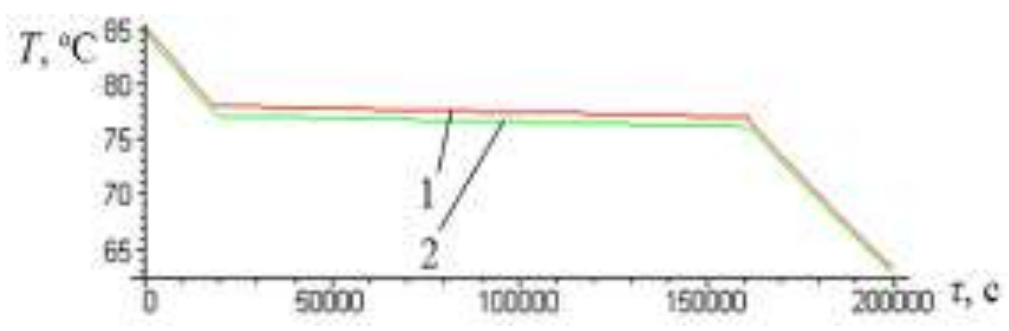

c)

Figure 17. The results of solving the system of equations (13) for a fourcylinder engine, heat accumulator, and circulation system using different design solutions of the HA in the second stage: 
a) - discharging of the heat accumulator at the standard mode of operation,

$b)$ - charging from a warmed-up engine,

$$
\text { c) - idle of a charged battery. }
$$

1 - discharging of heat-accumulating substance, 2 - warming up of cooling liquid, 3 - warming up of the engine.

We have noticed from the results of calculations, the system with the specified parameters is acceptable for efficient heating for a satisfactory period of time of about $200 \mathrm{~s}$ (Fig. 17, a), charging from a warmed engine is about $500 \mathrm{~s}$ (Fig. 17, b), acceptable conditions for charging are maintained in the heat accumulator at correctly picked up thermal insulation within 2 days (Fig. 17, c).

\section{For option 2}

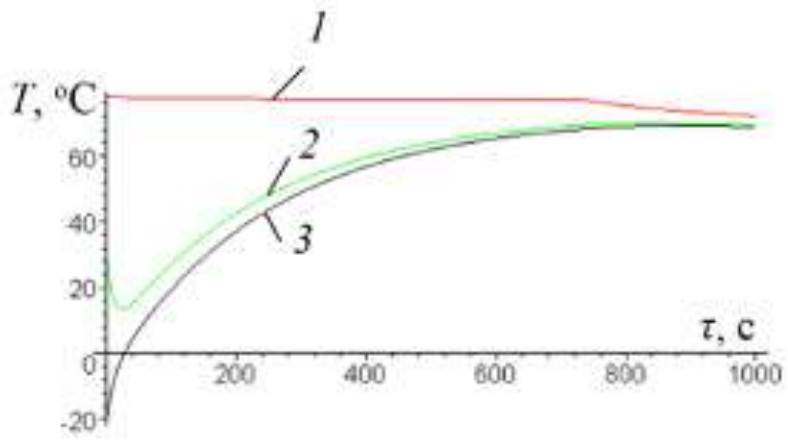

a)

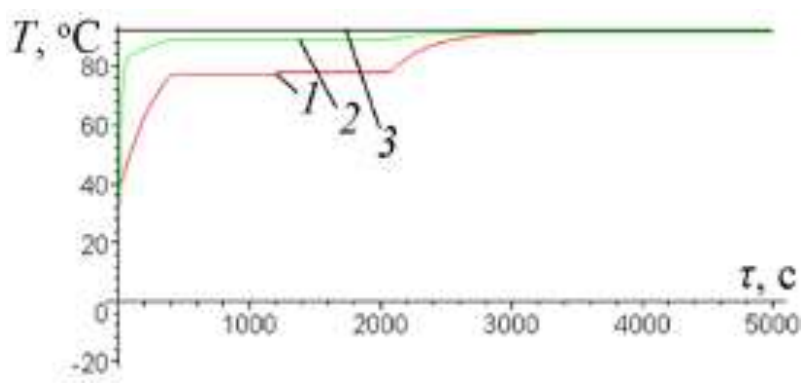

b)

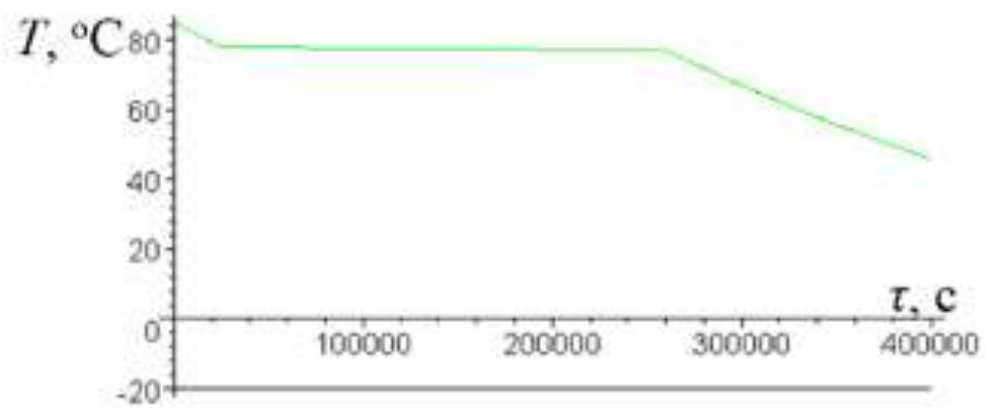

c)

Figure 18. The results of numerical calculations of the stages of thermal preparation of the internal combustion engine (the second option of the layout).

The symbols are the same as for fig. 17.

As we see from the results of calculations, the system according to the second option is more suitable for efficient heating for a satisfactory period of time of about 
$600 \mathrm{~s}$ (Fig. 18, a), charging from a warmed engine is about $2000 \mathrm{~s}$ (Fig. 18, b), acceptable for charging conditions are stored in the heat accumulator at correctly picked up thermal insulation within 4 days (Fig. 18,c) that is twice more, than under the first option of execution of the heat accumulator.

\section{For option 3}

Below is the numerical solution of the system (13) for the model of the engine with HA for one, three, and six tubes (Fig. 19).

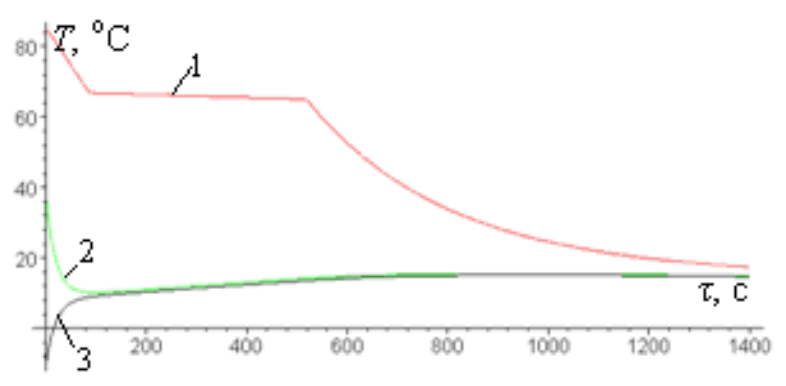

a)

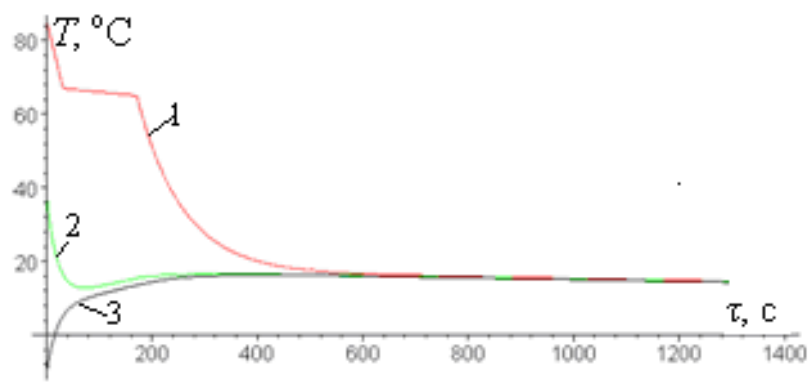

c)

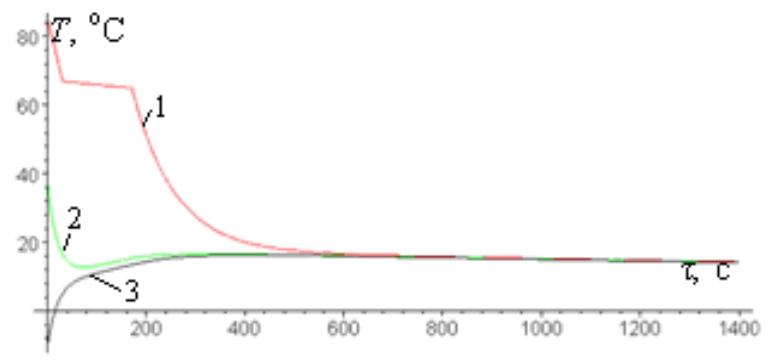

b)

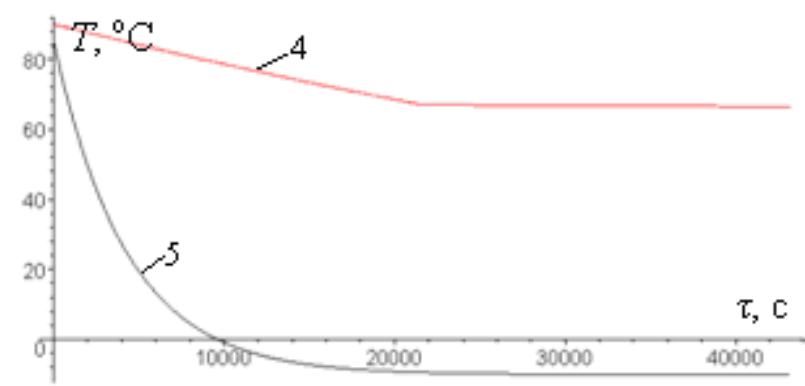

d)

Figure 19. The results of numerical calculations of the stages of thermal preparation of the internal combustion engine (the first version of the layout):

a) - the discharge process (1 U-shaped tube), b) - the discharge process

(3 U-shaped tubes), c) - the process of discharging (6 U-shaped tubes), d) - idle time of HA.

1 - discharging of the heat-accumulating substance, 2 - warming up of cooling liquid, 3 -warming up of the engine; 4 - liquid cooling;

5 - engine cooling. 
According to the results of calculations, we see that in terms of heating efficiency and economical efficiency in the perspective of metal consumption is the most profitable option for a heat accumulator with three tubes.

\section{The fourth stage is the creation of a bench model.}

At the last stage, we created a bench model with the implementation of field evidence. Here it is necessary to consider the basic requirements to the bench, namely, the bench should allow carrying out experiments:

— with different heat-accumulating materials, determining their efficiency (heat capacity, thermal conductivity, etc.) in conditions as close as possible to real;

- with various heat-insulating materials, determining the rate of self-discharge;

— with different shapes, sizes, and mutual arrangement of capsules, determining the rate of heat transfer (charging and discharging time of the heat accumulator);

- with different directions of fluid flow inside the heat accumulator to increase efficiency;

— determination of the insertion points of the heat accumulator pipes into the regular cooling system to ensure maximum efficiency.

We designed a bench (Fig. 20) to simulate the operation of the heat accumulator in real conditions. It consists of a heat accumulator, a pump that creates forced circulation of liquid, a full-size (complete) internal combustion engine, damper system to control fluid flow. 


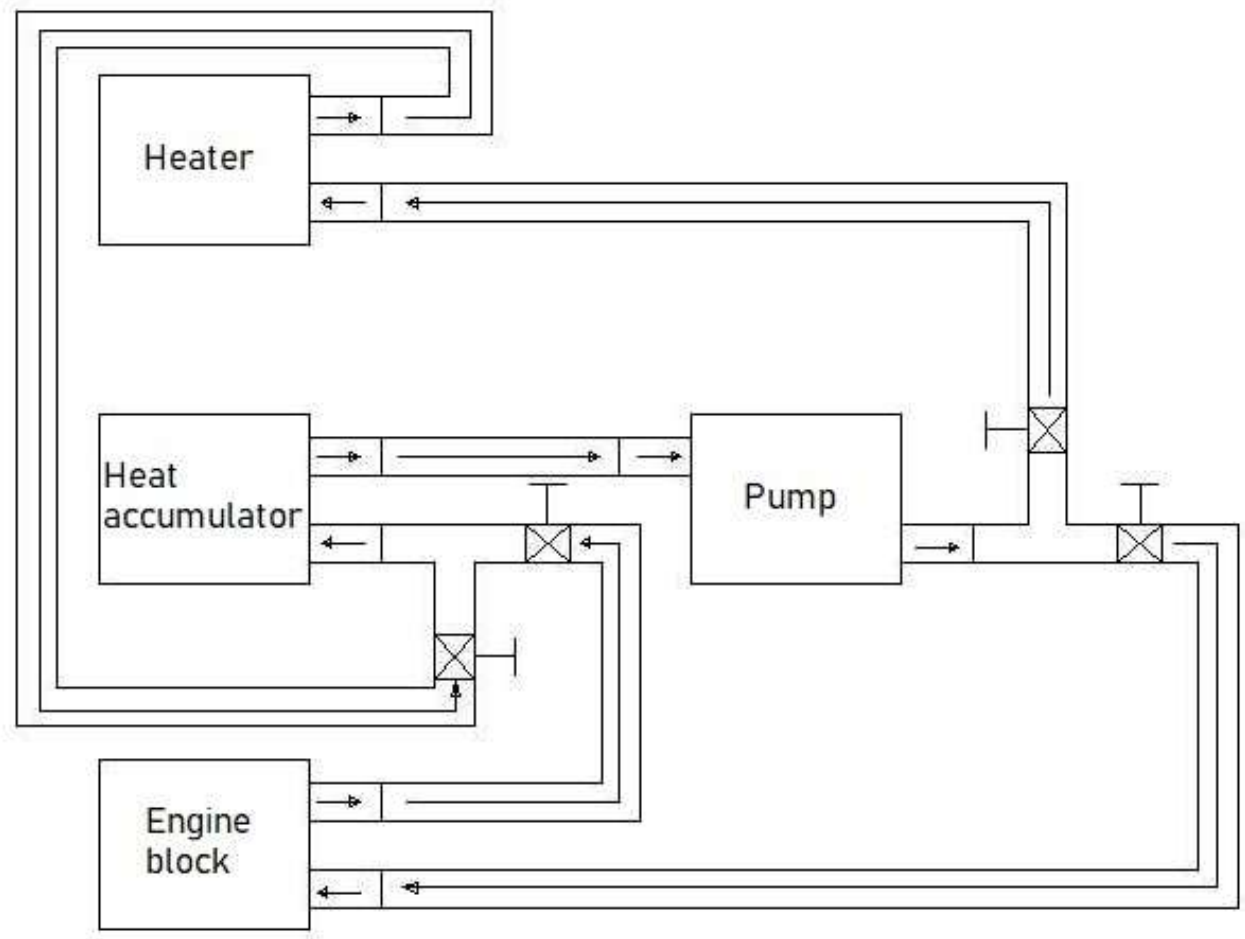

Figure 20. Bench to simulate the operation of the heat accumulator.

The heat accumulator in this scheme is a shell-and-tube heat exchanger with Ushaped tubes through which the tosol cooling agent moves, and in the intertube space, there is a heat-accumulating material ozokerite.

Heater - a capacity with a built-in tubular electric heater required to charge the battery. This unit allows us to simulate the operation of an internal combustion engine.

The initial stage of the experiment is the heating of the liquid in the heater and its circulation through the heat accumulator in order to melt the heat accumulating substance. We measured the temperature of the liquid in the heat accumulator at regular intervals to control the charging speed during the charging process. At the same time, gates prevent hit of the heated liquid in the engine. At the end of the charging process, the heating element is turned off, and we fed the liquid heated from the molten HAM to the internal combustion engine unit. The process continues until the onset of thermal equilibrium, which is characterized by the cessation of the increase in engine temperature. In the process of warming up, at regular intervals, the temperature of different parts of the engine unit is measured and a graph of the temperature change of 
this area over time is built. In addition, after the charging process was maintained for a period of time, simulating the process of heat storage.

The proposed stand was universal for experiments:

- with different heat-accumulating materials, determining their efficiency (heat capacity, thermal conductivity, etc.) in conditions as close as possible to real;

— with various heat-insulating materials, determining the rate of self-discharge;

— with different shapes, sizes, and relative positions of the tubes (or capsules in the case of the capsule version of the HA), determining the rate of heat transfer (charging and discharging time of the heat accumulator);

- with different directions of fluid flow inside the heat accumulator to increase efficiency;

— determination of the insertion points of the heat accumulator pipes into the regular cooling system to ensure maximum efficiency.

In fig. 21 shows the operation of the heat accumulator during bench tests (for the design according to option 3). We heated the heat accumulator by the electric heater 5, in our case by $1.5 \mathrm{~kW}$. We performed the tests only after heating the heat-accumulating substance to a temperature of $80^{\circ} \mathrm{C}$. Cold liquid is contained in the storage tank 1 , from which after opening the tap 2 flows through pipeline 3 connecting the storage tank with the heat accumulator, passes through the heat accumulator 4 , and sequentially through pipeline 6 containing temperature control sensors $t_{2}, t_{3}$ enters the storage tank for heated substances 7 . 


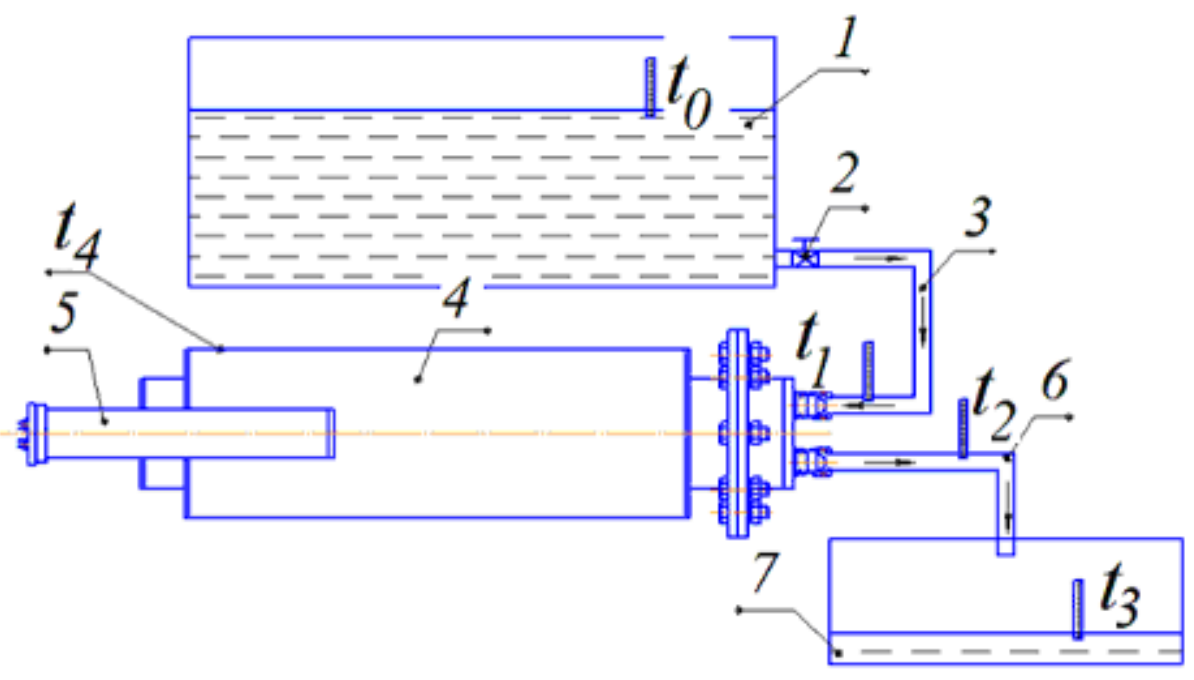

Figure 21. The bench scheme for testing HA.

1 - the storage tank with cold liquid, 2 - the crane, 3,6 - pipelines,

4 - the heat accumulator, 5 - electric heater, 7 - storage tank with the heated liquid.

We calculated the amount of heat from HAM to the liquid in one pass as

$$
Q=c_{l} G_{l}\left(t_{2}-t_{1}\right)
$$

where $c_{l}$ - heat capacity of the substance $($ water $)=4200 \frac{\mathrm{J}}{\mathrm{kg} \cdot \mathrm{K}}$;

$G_{l}-$ mass flow of liquid,

$$
G_{l}=V \rho,
$$

where $V$-volume consumption; $\rho=1000 \mathrm{~kg} / \mathrm{m}^{3} ; V=\frac{300 \mathrm{ml}}{35 \mathrm{~s}}=0,0000857 \mathrm{~m}^{3}$.

$$
Q=4200 \cdot 0,00857(23-5)=647,89 \mathrm{~J} .
$$

The amount of heat lost to the environment is equal to:

$$
Q_{e n v}=\alpha\left(t_{4}-t_{e n v}\right) F
$$

where $\alpha$ - heat transfer coefficient to the environment, $\mathrm{W}$;

$F$ - the surface area of the heat interchanger shell $\left(0,32 \mathrm{~m}^{2}\right)$.

$$
Q_{\text {env }}=10(89-5) \cdot 0,32=268,8 \mathrm{~J} \text {. }
$$

Thus, we see the need for additional external insulation. 
We conducted the studies in the following sequence. Cold liquid (tosol cooling agent) with a temperature equal to the ambient temperature $t_{\text {env }}=5{ }^{\circ} \mathrm{C}$, under gravitational motion, passed through the tubular space of the heat accumulator, taking away the heat accumulated in HAM. In the first stage of the experiment, the temperature of HAM was maintained at a constant value of $t_{\mathrm{HAM}}=80^{\circ} \mathrm{C}$ due to the circulation of hot liquid (tosol cooling agent) in the shell. As a result, we obtained a set of values of fluid temperatures at the outlet after heat exchange, shown in the graph (Fig. 22 - the dependence of $\Delta T$ on time).

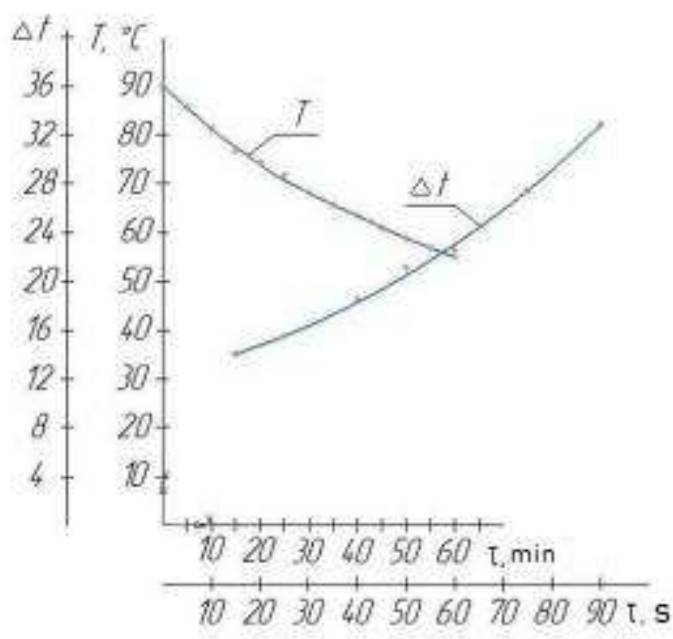

Figure 22. Graphs of temperature difference and HAM temperature change during cooling over time.

After conducting experiments and obtaining data, we can conclude that the volume of liquid $300 \mathrm{ml}$ in half a minute is heated to $15^{\circ} \mathrm{C}$. Given that each tube has one liter of coolant (total volume of 3 liters), we have heating of one liter for approximately $3 \cdot 0,5 \mathrm{~min}=1,5 \mathrm{~min}-$ one and a half minutes when the temperature changes by 15 degrees. Thus, three liters, which are the volume of a small cooling circuit, can be expected to warm up to $15^{\circ} \mathrm{C}$ in the same minute and a half when passing through three tubes. The temperature sufficient for an easy start-up can be expected, thus, in 3-4 minutes. 
The temperature of the heating element is $90{ }^{\circ} \mathrm{C}$, and the ambient temperature is $6{ }^{\circ} \mathrm{C}$. Depending on the difference in these temperatures, the time of complete phase transition of the heat-accumulating material varies from one to one and a half hours. Graph of cooling HAM without thermal insulation (Fig. 22, the dependence of $T$ on time).

Given the values of coolant temperatures obtained at the beginning of the experiment and the end, it becomes possible to predict changes in temperature over time and environmental conditions.

\section{Field tests and creation of the industrial design}

Further development of the design study, and operating conditions of the heat accumulator was the creation of an industrial design and testing of its operation.

In the proposed model of the heat accumulator as a heat-accumulating material of the phase transition was used ozokerite [melting point $56.5-76.0^{\circ} \mathrm{C}$ (in our case 67 ${ }^{\circ} \mathrm{C}$ ), specific enthalpy of melting (crystallization) $140.6 \mathrm{~kJ} / \mathrm{kg}$, density and specific heat at temperature $40{ }^{\circ} \mathrm{C}$ respectively $1076 \mathrm{~kg} / \mathrm{m}^{3}$ and $\left.3.151 \mathrm{~kJ} /(\mathrm{kg} \cdot \mathrm{K})\right]$; maintaining TAM in the molten state during engine operation was due to the heat of the coolant - tosol cooling agent, and heating and melting HAM in case of solidification after prolonged idle time was carried out using a tubular heating element (THE).

The experimental setup was a closed system of HA - a small circuit of the engine cooling system (ECS) of the car VAZ 2109 (Fig. 23).

The heat accumulator represents two coaxial cylindrical capacities. The inner storage tank is a shell-and-tube heat exchanger with U-shaped tubes through which the tosol cooling agent moves and the intertube space is filled with heat-accumulating material. The gap between the two cylinders contains a heat-insulating liquid (for example, water or antifreeze), there is a built-in the THE. 


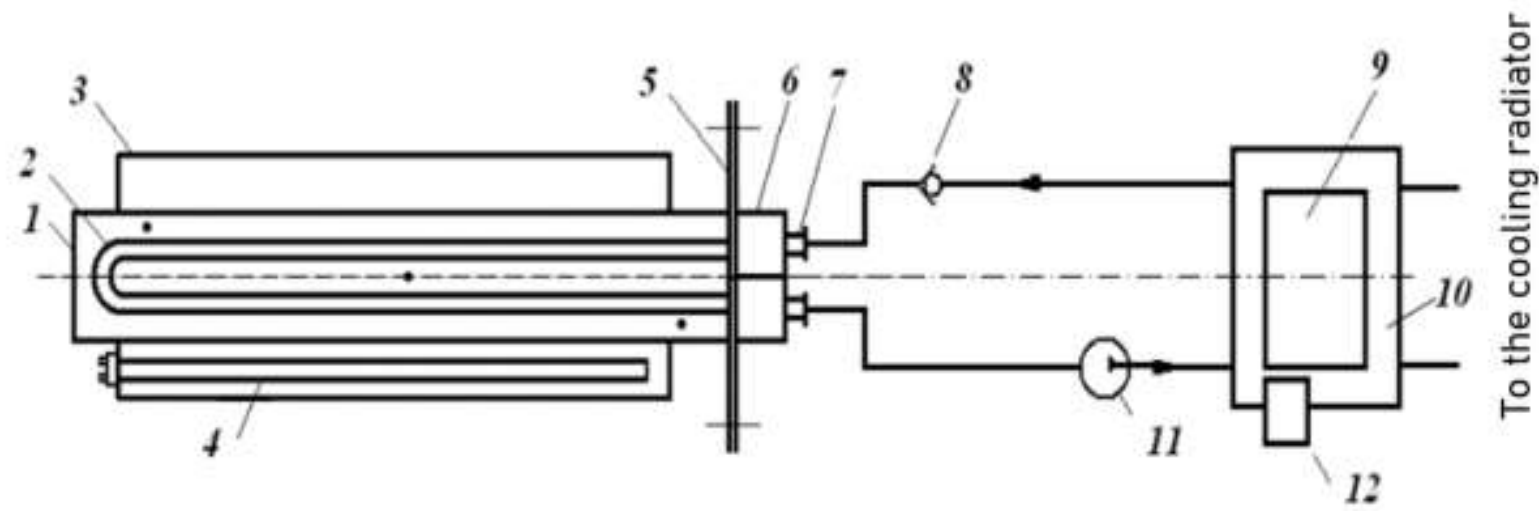

Figure 23. Experimental sample of the heat accumulator of the phase transition: 1 - cylindrical tank filled with ozokerite; 2 - U-shaped tube for tosol cooling agent circulating in the HA circuit - the engine cooling system (the number of tubes may vary); 3 - container filled with heat-insulating liquid;

4 - THE; 5 - pipe lattice; 6 - cover; 7 - branch pipes for input and output of tosol cooling agent; 8 - solenoid valves; 9 - engine; 10 - engine cooling shell; 11 - pump system of HA, 12 - engine cooling system pump.

Dots mark the places of the HAM temperature measurement.

The amount of antifreeze in the U-shaped tubes is additional to that of the tosol cooling agent contained in the small SOD circuit. Therefore, to maintain a constant volume of antifreeze in the cooling system in the absence of the need for TA (for example, when moving the car), the latter with the help of solenoid valves is removed from the ECS, and if necessary re-introduced.

The experimental sample of the heat accumulator has thermocouples to study the temperature changes of HAM and tosol cooling agent during the charging and discharging of the HA. Temperature measurement points of HA are shown in Fig. 1, the temperature of the tosol cooling agent was measured at the entrance to the outlet and out of it. We took average values of temperatures to plot. Charging of the HA is called heating HAM to a temperature close to the temperature of the running engine, and discharging - the end of the crystallization process of HAM. It should be noted 
that HAM can be cooled to ambient temperature when the stop engine for some time, which can also be used when the engine starts.

After obtaining experimental data on changes in ozokerite and tosol cooling agent temperatures over time, we determined the time required to charge and discharge the heat accumulator.

In fig. 24 shows the heating curves of HAM and tosol cooling agent from the warmed-up engine (charging of the HA). Ozokerite at a temperature below $67{ }^{\circ} \mathrm{C}$ is in the solid state. When the temperature rises to $67^{\circ} \mathrm{C}$, which occurs in about $100 \mathrm{~s}$, it begins to melt (horizontal section of line 3 ) and becomes liquid in $\sim 300 \mathrm{~s}$, and then the liquid ozokerite is heated to the temperature of tosol cooling agent, which in turn is heated by the engine, cooling the latter.

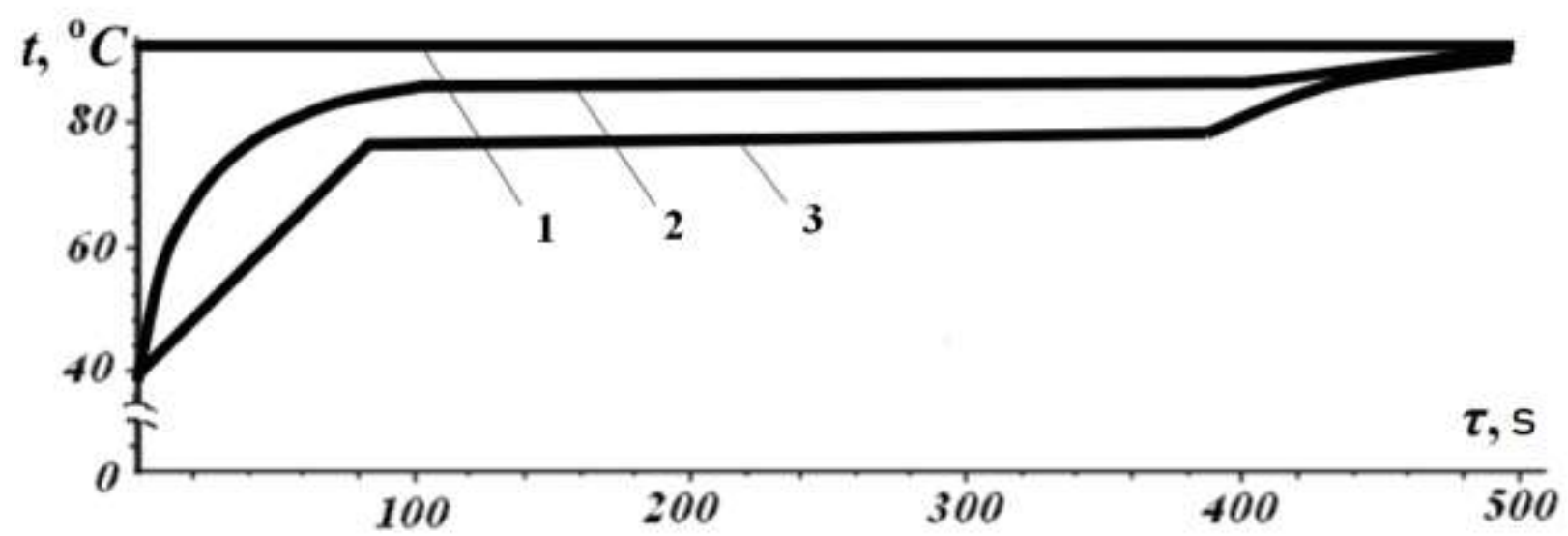

Figure 24. The HA charging and heating the tosol cooling agent from the warmed-up engine (car movement): 1 - engine temperature; 2 - tosol cooling agent temperature; 3 - HA temperature.

Thus, if the engine is already warmed up, it takes about $500 \mathrm{~s}$ or 8 minutes to charge the HA from a temperature of $40{ }^{\circ} \mathrm{C}$. This means that shortly before stopping 
the car, the heat accumulator must be included in the engine cooling system to charge it.

When it is necessary to start the engine, the pump of the HA system 11 is switched on. There is the mixing of the tosol cooling agent, which was in HA (its temperature is close to the crystallization temperature of HAM), with the rest of the tosol cooling agent, which was in the shell of the cooling system (temperature close to ambient temperature), while the tosol cooling agent temperature decreases. The resulting temperature of the tosol cooling agent depends on its mass (volume) and outside temperature. The volume of the tosol cooling agent in the HA can be adjusted by changing the number of $U$-shaped tubes (one tube had a volume of 0.2 liters). Thus, in our experiments, the number of tubes varied from 1 to 6 , and the volume, respectively, was from 0.2 liters to 1.2 liters.

Tables 2 and 3 show the calculations of the amount of heat given off by the tosol cooling agent in the heat accumulator and received by the tosol cooling agent from the ECS. Based on the heat balance, we determined the temperature of the mixture of two parts of tosol cooling agent - in HA ( $\left.t_{\text {тол.НА }}\right)$ and in the shell of ECS ( $\left.t_{\text {тos.eng. }}\right)$ (Table 2$)$.

The temperature of tosol cooling agent in HA according to experimental data was $65^{\circ} \mathrm{C}$, the volume of tosol cooling agent in the cooling system in our experiments was 31 , the physical parameters of tosol cooling agent were taken at $40^{\circ} \mathrm{C}$.

As a option of the already considered design solution, the design of a heat accumulator is proposed, in which water with a tubular electric heater immersed in it is in a single housing, and a phase-transient HAM, in the layer of which a liquid heat exchanger is placed.

A spiral (Fig. 25, a) or coil heat exchanger with coils located parallel (Fig. 25, $b$ ) or perpendicular (Fig. 25, c) to the axis of the heat accumulator is used as a liquid heat exchanger. 


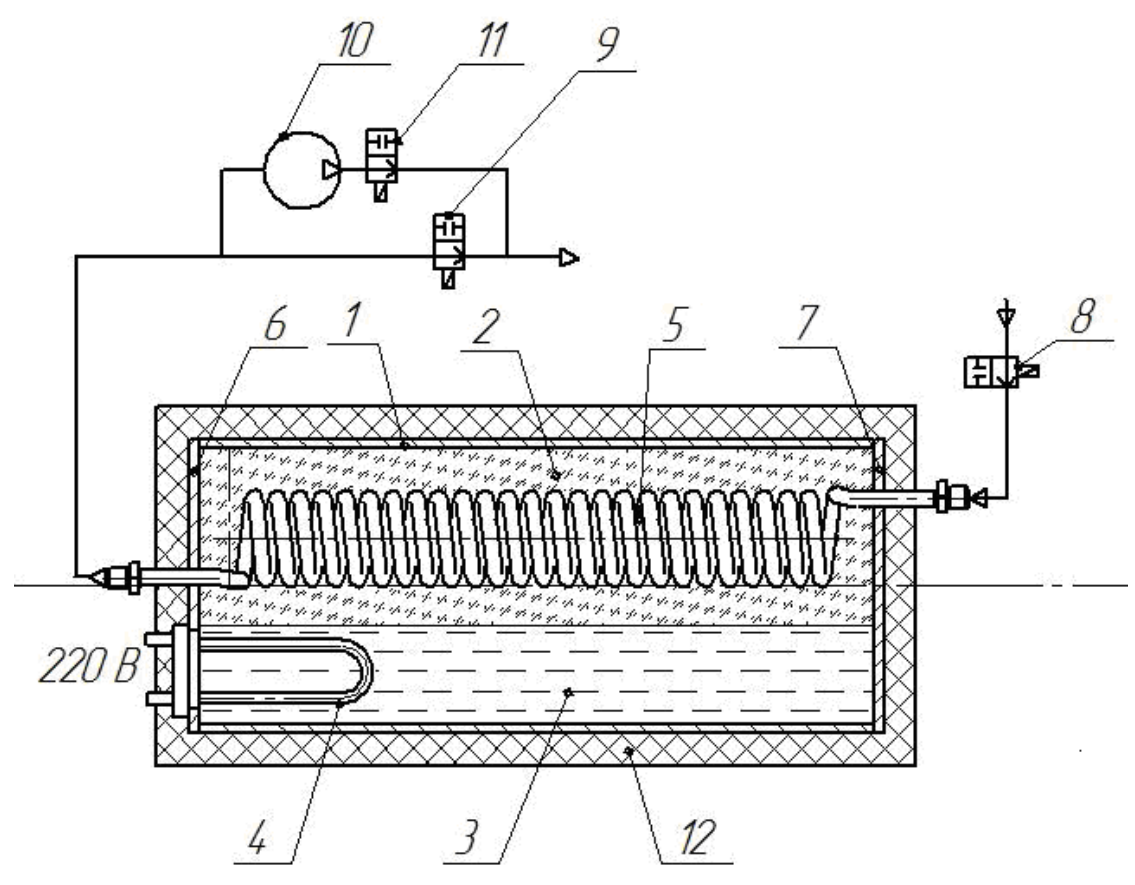

a)
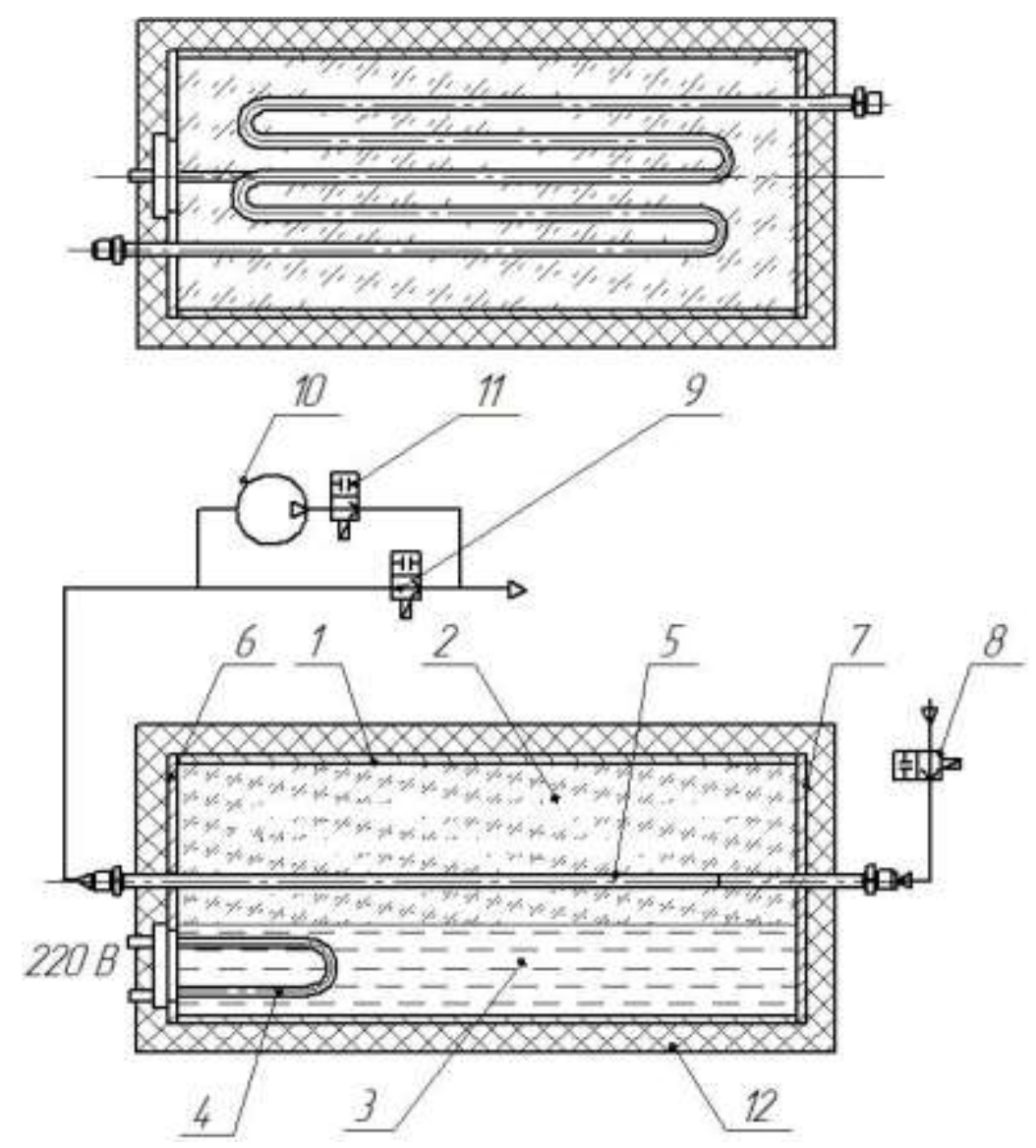

b) 


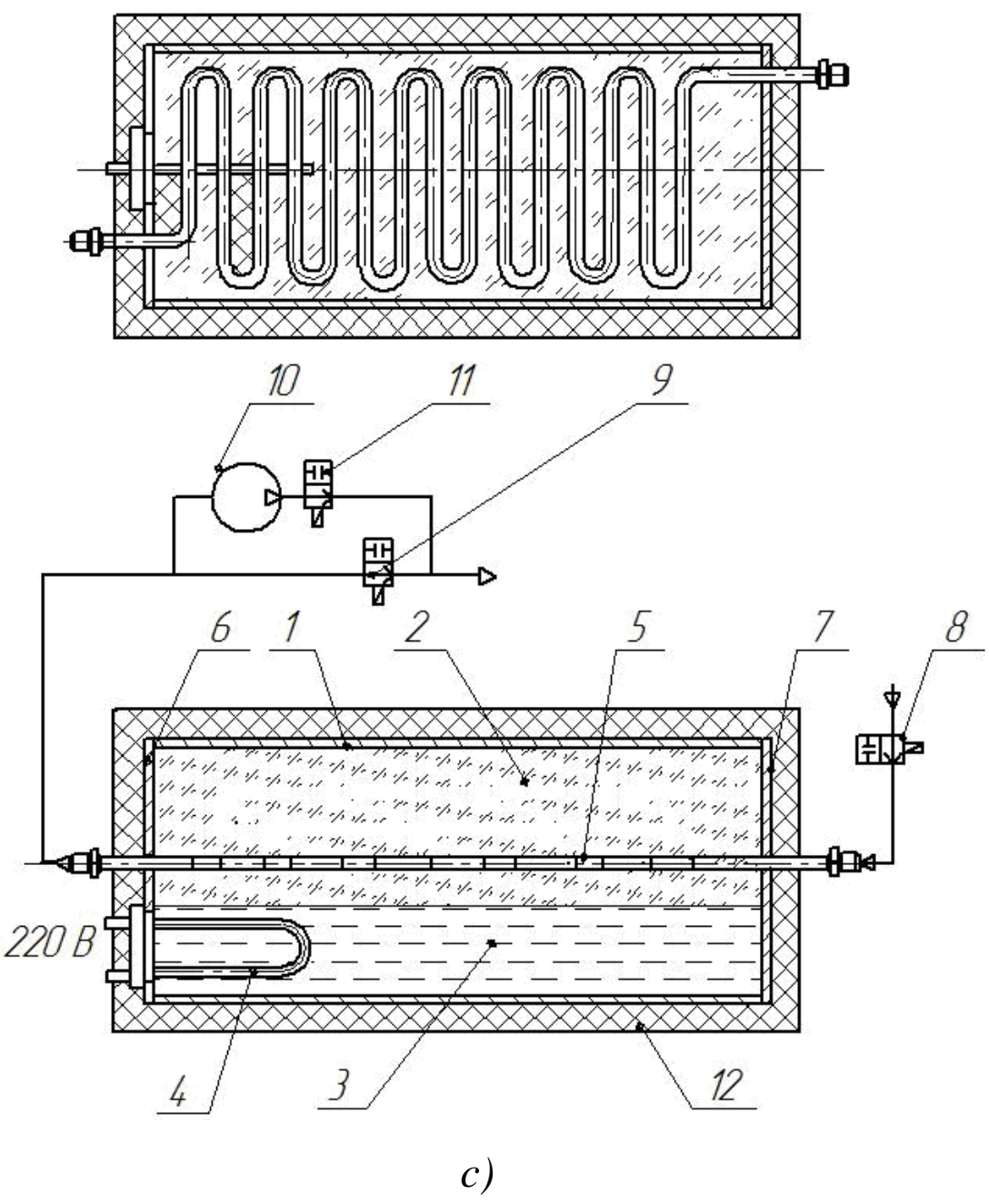

Figure 25. Heat accumulator:

a) - spiral; b) - coiled with convolutions of the heat exchanger, located parallel to the axis of HA; c) - coiled with convolutions of the heat exchanger, located perpendicular to the axis of HA.

1 - airtight casing; 2 - HAM; 3 - water; 4 - THE; 5 - the heat exchanger; 6, 7 pipe gratings; $8,9,11$ - solenoid valves; 10 - pump; 12 - heat-insulating material. 
Table 2

The amount of heat given off by the tosol cooling agent in the heat accumulator depending on the weight of the tosol cooling agent

\begin{tabular}{|c|c|c|}
\hline $\begin{array}{c}\text { Tosol } \\
\text { temperature } \\
\text { in HA } \\
t_{\text {Tos.HA }}\end{array}$ & $\begin{array}{c}\text { Volume of } \\
\text { tosol in } \\
\mathrm{HA}, \mathrm{m}^{3}\end{array}$ & $Q, \mathrm{~kJ}$ \\
\hline \multirow{3}{*}{65} & $1,2 \cdot 10^{-3}$ & $Q=c m\left(t_{\text {Tos.HA }}-t_{\text {Tos.eng. }}\right)=3,151 \cdot 1,2 \cdot 10^{-3} \cdot 1076\left(65-t_{\text {Tos.eng. }}\right)=264,46-4,07 t_{\text {Tos.eng }}$ \\
\cline { 2 - 4 } & $0,6 \cdot 10^{-3}$ & $Q=132,23-2,03 t_{\text {Tos.eng }}$ \\
\cline { 2 - 3 } & $0,2 \cdot 10^{-3}$ & $Q=44,08-0,68 t_{\text {Tos.eng }}$ \\
\hline
\end{tabular}

Table 3

The amount of heat received by the tosol cooling agent in the engine cooling jacket, depending on the ambient temperature $\left(t_{\mathrm{ext}}\right)$

\begin{tabular}{|c|c|c|}
\hline$t_{\mathrm{ext}}$ & $\begin{array}{c}\text { The } \\
\text { amount } \\
\text { of tosol } \\
\text { in ECS, } \\
\mathrm{m}^{3}\end{array}$ & $Q, \mathrm{~kJ}$ \\
\hline 10 & \multirow{5}{*}{$3 \cdot 10^{-3}$} & $Q=c m\left(t_{\text {ros.eng. }-} t_{\text {ext }}\right)=3,151 \cdot 3 \cdot 10^{-3} \cdot 1076\left(t_{\text {ros.eng }}-10\right)=10,17 t_{\text {ros.eng. }}-101,71$ \\
\hline 5 & & $Q=3,151 \cdot 3 \cdot 10^{-3} \cdot 1076\left(t_{\text {Tos.eng }}-5\right)=10,17 t_{\text {Tos.eng. }}-50,85$ \\
\hline 0 & & $Q=3,151 \cdot 3 \cdot 10^{-3} \cdot 1076\left(t_{\text {Tos.eng }}-0\right)=10,17 t_{\text {Tos.eng }}$ \\
\hline-5 & & $Q=3,151 \cdot 3 \cdot 10^{-3} \cdot 1076\left(t_{\text {Tos.eng }}+5\right)=10,17 t_{\text {Tos.eng. }}+50,85$ \\
\hline-10 & & $Q=3,151 \cdot 3 \cdot 10^{-3} \cdot 1076\left(t_{\text {Tos.eng }}+10\right)=10,17 t_{\text {Tos.eng. }}+101,71$ \\
\hline
\end{tabular}

Solving the heat balance equation, we find the temperature of the tosol cooling agent depending on its volume in the HA and the ambient temperature. The calculation data are given in table. 4 .

Table 4

The temperature of the mixture of tosol cooling agent formed after mixing the tosol cooling agent in the HA with the tosol cooling agent of the engine cooling shell

\begin{tabular}{|c|c|c|c|c|c|}
\hline $\begin{array}{c}\text { The amount of } \\
\text { tosol cooling agent } \\
\text { in the HA, } 1\end{array}$ & 10 & 5 & 0 & -5 & -10 \\
\cline { 2 - 6 } & 25,7 & 22,1 & 18,6 & 15 & 11,4 \\
\hline 1,2 & 19,0 & 15,0 & 10,8 & 6,7 & 2,5 \\
\hline 0,6 & 13,4 & 8,7 & 4,1 & 0,6 & $-5,3$ \\
\hline 0,2 & & & & & \\
\hline
\end{tabular}


To address the question of the mass of the HAM contained in the heat accumulator, we performed experiments on the effect of the mass of the HAM on the time of discharging of the HA. In fig. 26 shows the curves of ozokerite cooling from a temperature close to the temperature of the running engine to the ambient temperature, which was $5{ }^{\circ} \mathrm{C}$. Here on the upper abscissa is the time related to the cooling of the HA without thermal insulation. We see that at a HAM mass of $5.6 \mathrm{~kg}$ discharging of HA occurs after $600 \mathrm{~s}(10 \mathrm{~min})$, while heat-insulated HA is discharged in 8 hours. With decreasing the HAM mass discharge of HA occurs faster.

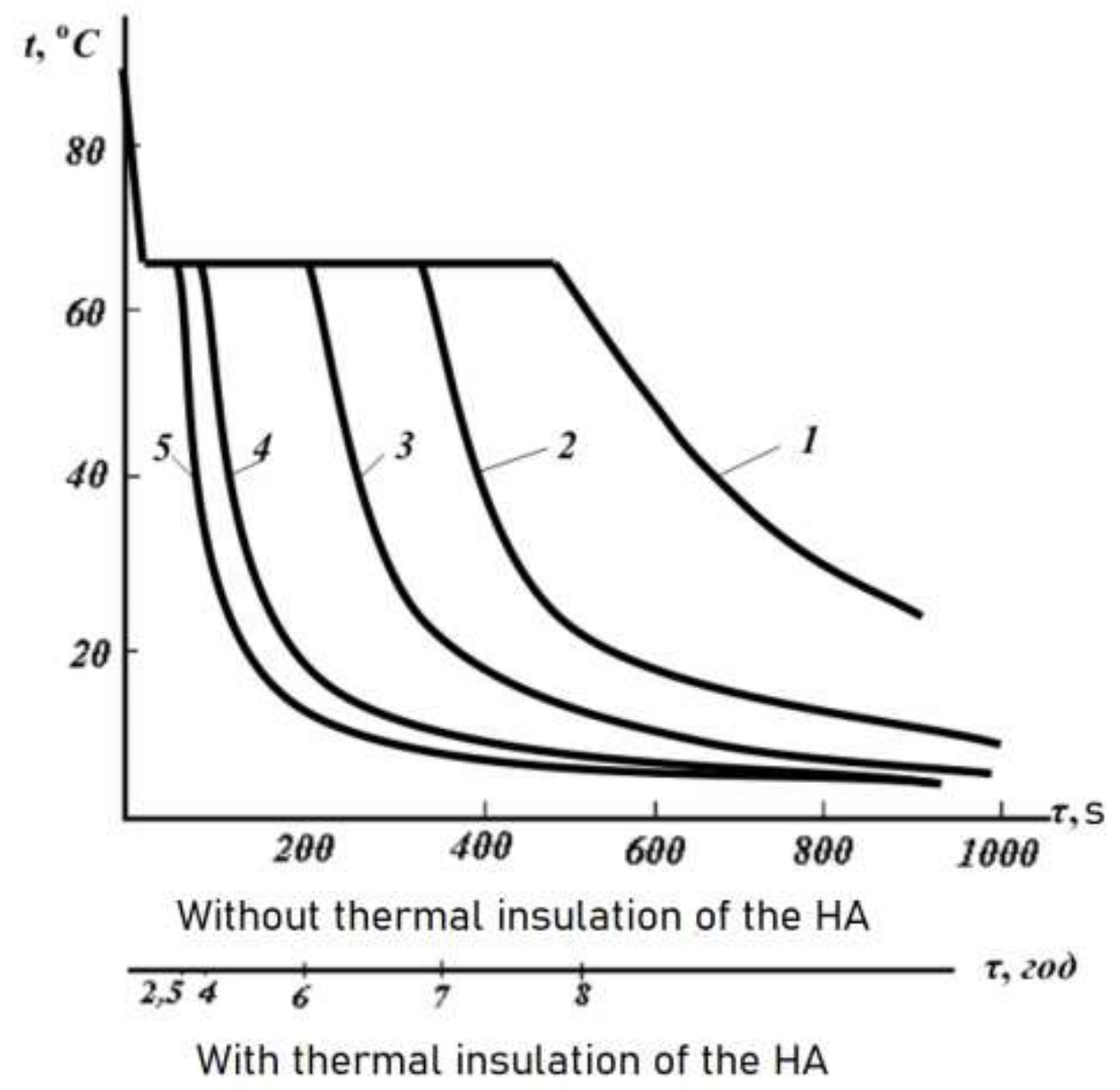

Figure 26. Discharging of the heat accumulator at different masses of HAM:

1 - mass of HAM 5,6 kg $\left(0,0052 \mathrm{~m}^{3}\right) ; 2-5,16 \mathrm{~kg}\left(0,0048 \mathrm{~m}^{3}\right) ; 3-4,52 \mathrm{~kg}(0,0042$ $\left.\mathrm{m}^{3}\right) ; 4-3,2 \mathrm{~kg}\left(0,0030 \mathrm{~m}^{3}\right) ; 5-2,7 \mathrm{~kg}\left(0,0025 \mathrm{~m}^{3}\right)$. 
The dependence of the discharge time of the heat accumulator on the HAM mass is presented in Fig. 27. These data can be the basis for calculating the dimensions of the heat accumulator.

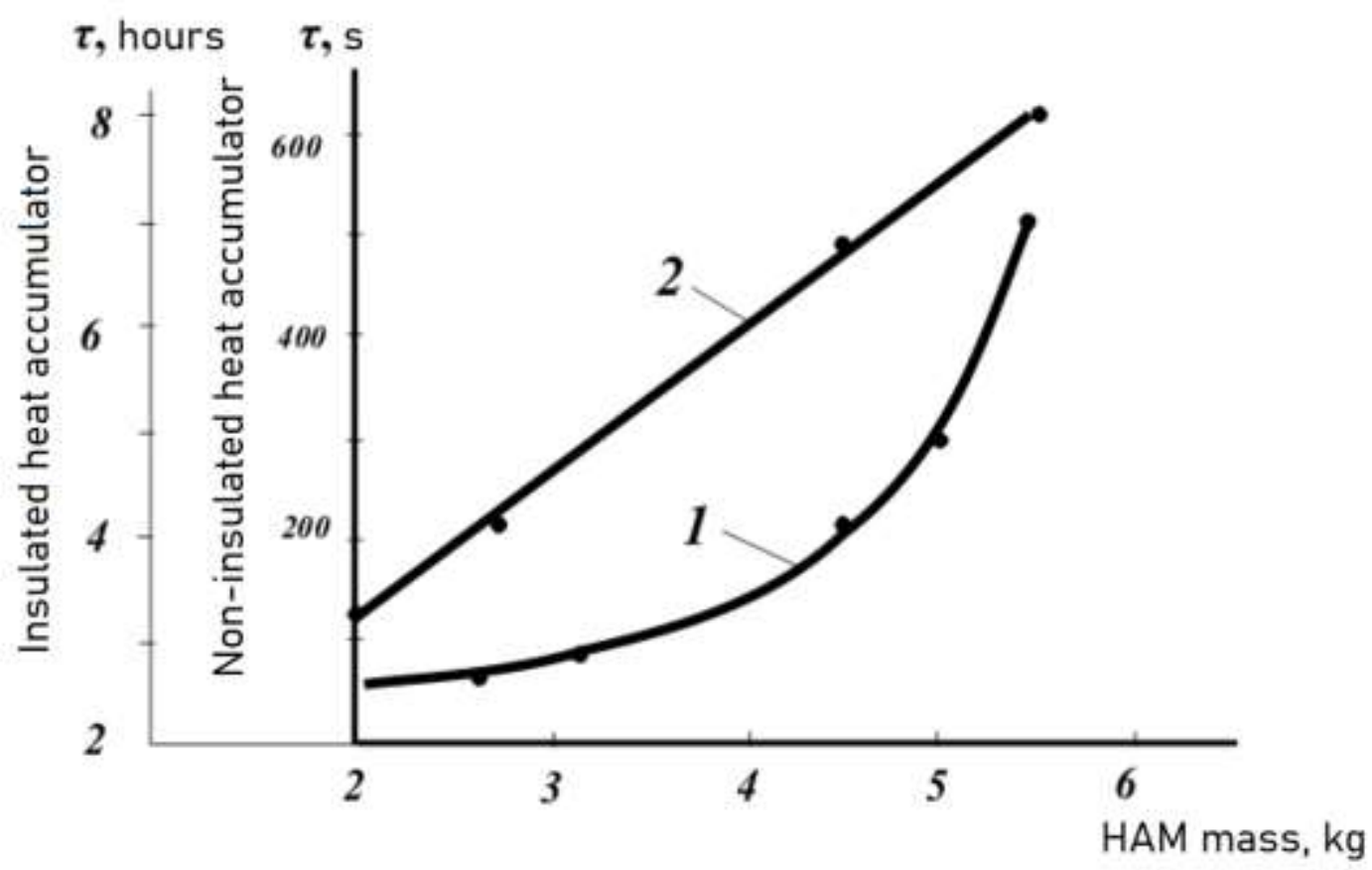

Figure 27. The dependence of the discharge time of the heat accumulator on the HAM mass:

1 - Non-insulated heat accumulator; 2 - Insulated heat accumulator (thermal insulation - a layer of mineral wool $50 \mathrm{~mm}$ thick).

The data given in table. 4 on the temperature of the antifreeze, allow you to calculate the HAM mass required to ensure warm-up of the engine. The calculation was performed from the heat balance between the amount of heat required to heat the antifreeze from its temperature after stirring to the starting temperature of the engine and the amount of heat released during crystallization HAM:

$$
Q_{\text {heated. }}=c_{\text {Tos. }} m_{\text {Tos. }}\left(t_{\text {eng. }}-t_{\text {amount.ros. }}\right) ; \quad Q_{\text {crystall. }}=m_{\mathrm{HAM}} \cdot r,
$$

Thus, at a weight of tosol cooling agent of $3.44 \mathrm{~kg}$ (volume $3.21-31$ in the cooling system and 0.21 in the tube of HA) and an external temperature of $5{ }^{\circ} \mathrm{C}$ with stirring, the temperature of the tosol cooling agent is $8.7{ }^{\circ} \mathrm{C}$, the temperature of the 
tosol cooling agent, required to warm up the engine to $40{ }^{\circ} \mathrm{C}$, is $50{ }^{\circ} \mathrm{C}$. Then the weight of HAM is $3.16 \mathrm{~kg}$ (volume 3 liters).

At an external temperature of $0{ }^{\circ} \mathrm{C}$, the mass of HAM is $3.85 \mathrm{~kg}(3.58 \mathrm{l})$, etc.

But, as evidenced by the data shown in Fig. 27, at a mass of HAM about $3 \mathrm{~kg}$ the HA is discharged in about 4 hours, and at a mass of about $4 \mathrm{~kg}-$ in 6 hours. If this time is not enough to keep the HA in a charged state, you need to strengthen the insulation.

Thus, the mass of HAM is determined depending on the ambient temperature and idle time of the car.

Our research has shown that to quickly start the engine it should be warmed up to $40{ }^{\circ} \mathrm{C}$, the tosol cooling agent temperature should be about $50{ }^{\circ} \mathrm{C}$. When the car stopped, its engine is cooled to temperatures at about one and a half hours (about 6000 s) (Fig. 28, $a$, curve 1), at which starting the car becomes difficult, and in 3 hours the engine temperature approaches the ambient temperature. Due to the heat released during its crystallization, the heat-accumulating material cools much more slowly (Fig. 28, a, curve 2). Thermal insulation of HA helps to reduce the cooling rate of HAM, as can be seen when comparing solid and dotted lines 2 (area I Fig. 28, a). Tosol cooling agent in HA has a temperature close to HAM. In the presence of thermal insulation of the HAM heat accumulator (and ozokerite of HA) maintains a high $\left(67^{\circ} \mathrm{C}\right)$ temperature for a long time (section $I$ in Fig. 28, a). We proposed design of the heat accumulator, and the discharge time was increased to 14 hours.

When engine starts the (section II in Fig. 28,a), the pump is turned on, which pumps the tosol cooling agent in a closed circuit HA-engine cooling system (ECS). The tosol cooling agent from HA $\left(65^{\circ} \mathrm{C}\right)$ is mixed with the tosol cooling agent from the cooling shell and the temperature of the mixture reaches about $9{ }^{\circ} \mathrm{C}$ (data of table. $4)$.

Due to the heat released during crystallization of HAM, the tosol cooling agent is heated to $\sim 50{ }^{\circ} \mathrm{C}$, and the engine is warmed up to $\sim 40{ }^{\circ} \mathrm{C}$, which allows you to quickly start. 
Thus, to quickly start the car engine at low temperatures requires that HAM is a long time in the crystallization stage (i.e., HA should not be discharged), and the temperature of the tosol cooling agent, which is in the ECS, was about $50{ }^{\circ} \mathrm{C}$.

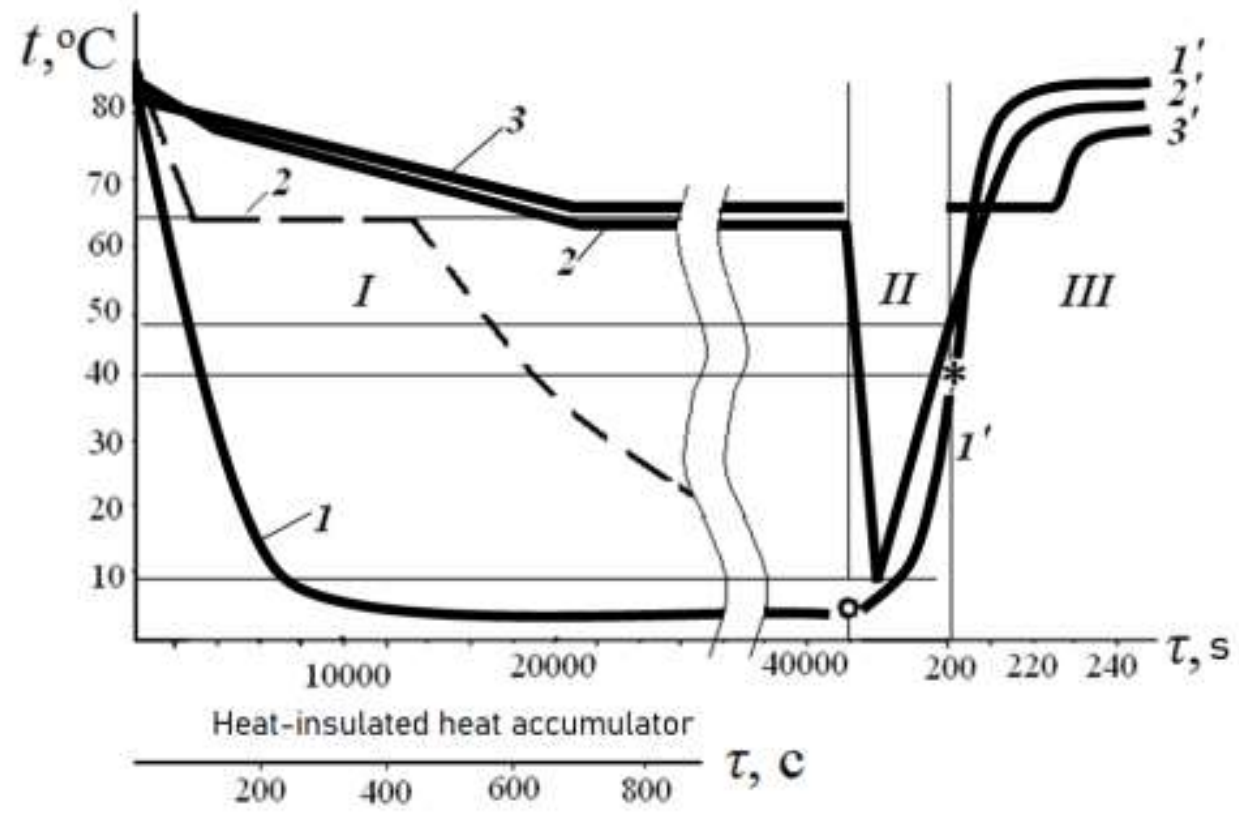

Non-insulated heat accumulator (dotted line)

o- switching on the pump * the engine start

a)

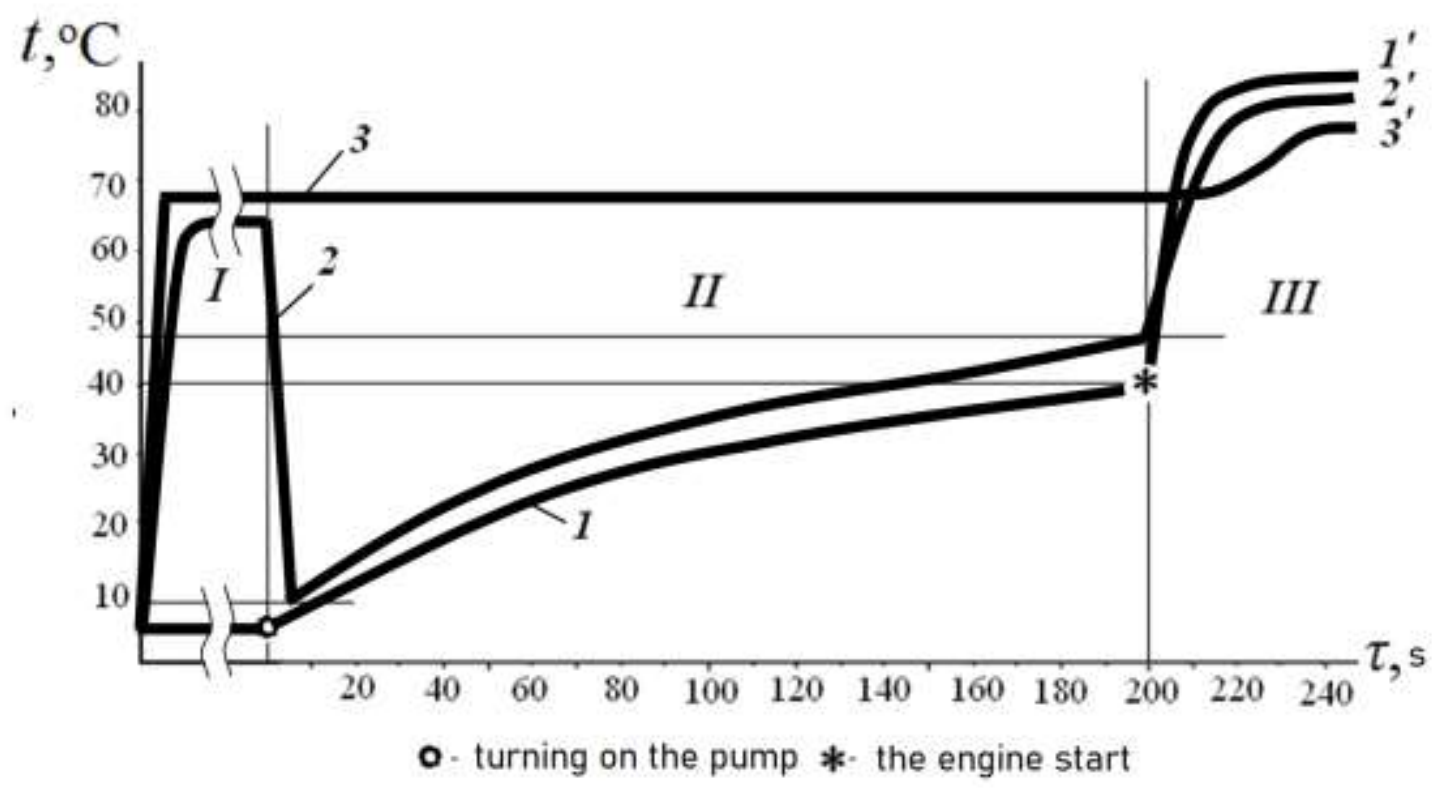

b)

Figure 28. Operating modes of the TA-SOD system:

a) - cooling of the engine and HAM when the car stands and the subsequent the engine start; $b$ ) - pre-start charging of HA and the subsequent engine start. 
$I$ - cooling area for $a$, heating with THE for $b ; I I$ - area of warming up and starting the car; $I I I$ - area of stable operation while driving;

1 - changing in engine temperature; 2 - tosol cooling agent; 3 - HAM.

At long-standing at low temperature the air of HAM completely turns to a solid-state, acquiring ambient temperatures, therefore preliminary heating and melting of heat-accumulating material using THE (area $I$ in fig. 28, $b$ ) is carried out. Changes in temperatures of HAM, tosol cooling agent during its heating and circulation in the cooling system of the engine and the engine itself have been studied. At a temperature of $67^{\circ} \mathrm{C}$ and above, when HAM goes to the molten state, the cooling system pump is turned on, the tosol cooling agent begins to circulate in the general system HA-ECS, while it is mixed and heated from the part of tosol cooling agent that was in the heat accumulator (section II in Fig. 28, b). The temperature of the mixture can be determined from the data in table. 3 , at ambient temperature, for example, $5{ }^{\circ} \mathrm{C}$ and the volume of tosol cooling agent in HA 0.21 , it will be about $9^{\circ} \mathrm{C}$. Further heating of the tosol cooling agent is due to the heat of crystallization of HAM. In about $200 \mathrm{~s}$ the temperature of tosol cooling agent reaches about $50{ }^{\circ} \mathrm{C}$, and the engine temperature $-40{ }^{\circ} \mathrm{C}$ (area $I I$ in Fig. $28, b$ ), while the engine starts in 5-10 s. Then the temperature of the engine, tosol cooling agent and HAM go to the regime values (area III in Fig. 28, $b$ ). Thus, at idle, the engine runs for a very short time, so you can avoid the negative consequences mentioned at the beginning of the article.

On the basis of the received experimental data and calculations the operating model of the heat accumulator was created. It differs from the experimental sample by the presence of solenoid valves on the nozzles of the tosol cooling agent in the heat exchanger and out of it.

Due to the fact that increasing the volume of coolant in the ECS is undesirable, one U-shaped tube (outer diameter $15 \mathrm{~mm}$, containing 0.2 liters of tosol cooling agent) was taken. To ensure the charged state of the heat accumulator for $14 \mathrm{~h}$, the mass of ozokerite was $6 \mathrm{~kg}(5.6 \mathrm{l})$ in the presence of thermal insulation of mineral wool with a 
thickness of $100 \mathrm{~mm}$. The diameter of the cylindrical tank with HAM - $110 \mathrm{~mm}$, length $-0.6 \mathrm{~m}$.

The developed heat accumulator for pre-heating of the internal combustion engine was tested on such cars as HAZ-3250 bus with NISSAN DONG FENG CY4102BZLQ engine and VAZ family of cars and proved its efficiency, which determines its wide application.

\section{Using the method of factorial experiment in the study}

\section{operating conditions of the heat accumulator in the system of pre-starting start of the automobile engine}

R. Fischer proposed using of the method of the factorial experiment in 1935 [293]. This method allows using the obtained regression equation to estimate the simultaneous influence of many factors on a quantity called the optimization parameter. In the science of our country, the method became widespread in the 60's and 80's of the last century for planning and analysis of experiments, in studying the properties of materials, in the search for optimal conditions of carrying out one or another processes.

Despite the wide possibilities, the method of factorial experiment had limitations calculations. Thus, within the prescribed period, the regression equations were easily solved for two-factor, marginally more difficult - for three-factor, and for four or more factors to obtain the regression equation became quite problematic.

The availability of accessible computing technics and software [294] has now allowed us to return to the use of the factor experiment method in various fields construction [295], energy saving [296], materials processing [297, 298], motor transport [299], agriculture [300], food industry [301-303], military sphere [304], etc. [305].

Using a heat accumulator (HA) in the prelaunch procedure system of the car engine in order to accelerate the engine start at low external temperatures, the most important indicator of the HA is the time of its discharging. Prolonged discharging time allows you to leave the car outdoors for a long time, especially at night. 
The previous studies have shown that the discharging time of the HA depends on the external temperature, the mass of the heat-accumulating material (HAM) and the thickness of the insulation layer. We used a full factorial experiment to predict the simultaneous action of these factors at the time of discharging HA [306]. In this case, we took the discharging time as the optimization parameter $y$.

As far as during performance of the experiments the variable factors are inhomogeneous and have different units of measurement, we reduce them to a unified system by going from the present values to the coded ones. We presented the factor coding results in table 5, the plan-matrix of the full factorial experiment - in table 6 , the experiments results and the estimated values of the HA discharging time - in table 7.

Table 5

Natural values of the factors and variability interval

\begin{tabular}{|l|c|c|c|c|}
\hline \multirow{2}{*}{ Factors } & \multirow{2}{*}{ Basic level } & $\begin{array}{c}\text { Variability } \\
\text { interval }\end{array}$ & \multicolumn{2}{c|}{ Levels } \\
\cline { 3 - 5 } & & 0,75 & 2 & 0,5 \\
\hline$x_{1}$ - mass of ozokerite in HA, kg & 1,25 & -10 & 5 & -15 \\
\hline$x_{2}-{\text { external temperature, }{ }^{\circ} \mathrm{C}}^{*} \begin{array}{l}x_{3}-\text { the thickness of the } \\
\text { insulation layer, } \mathrm{mm}\end{array}$ & 75 & 25 & 100 & 50 \\
\hline
\end{tabular}

Table 6

Plan-matrix of the full factorial experiment

\begin{tabular}{|c|c|c|c|c|c|c|c|c|}
\hline \multirow{2}{*}{$j$} & \multirow{2}{*}{$x_{0}$} & \multicolumn{7}{|c|}{ Planning (factors) } \\
\cline { 2 - 9 } & & $x_{1}$ & $x_{2}$ & $x_{3}$ & $x_{1} x_{2}$ & $x_{1} x_{3}$ & $x_{2} x_{3}$ & $x_{1} x_{2} x_{3}$ \\
\hline 1 & +1 & -1 & -1 & -1 & +1 & +1 & +1 & -1 \\
\hline 2 & +1 & -1 & -1 & +1 & +1 & -1 & -1 & +1 \\
\hline 3 & +1 & -1 & +1 & -1 & -1 & +1 & -1 & +1 \\
\hline 4 & +1 & -1 & +1 & +1 & -1 & -1 & +1 & -1 \\
\hline 5 & +1 & +1 & -1 & -1 & -1 & -1 & +1 & +1 \\
\hline 6 & +1 & +1 & -1 & +1 & -1 & +1 & -1 & -1 \\
\hline 7 & +1 & +1 & +1 & -1 & +1 & -1 & -1 & -1 \\
\hline 8 & +1 & +1 & +1 & +1 & +1 & +1 & +1 & +1 \\
\hline$b_{i}$ & 688,25 & 351,25 & 93,75 & 101,25 & 98,75 & 31,25 & $-46,25$ & $-1,25$ \\
\hline
\end{tabular}


Table 7

Experimental and calculated values of the heat accumulator discharging time

\begin{tabular}{|c|c|c|c|c|c|c|c|c|}
\hline \multirow{2}{*}{$j$} & \multicolumn{3}{|c|}{$\begin{array}{l}\text { Discharging time } \\
\min \end{array}$} & \multirow{2}{*}{$(\bar{\tau}-\tau)^{2}$} & \multirow{2}{*}{$S_{j}^{2}$} & \multirow{2}{*}{$\tau_{\text {calc }}$} & \multirow{2}{*}{$\bar{\tau}_{\text {exp.j- }-\tau_{\text {calc. }}}$} & \multirow{2}{*}{$\left(\bar{\tau}_{\left.\text {exp.j- }-\tau_{\text {calc. }}\right)^{2}}\right.$} \\
\hline & $\tau$ exp. 1 & $\tau_{\text {exp. } 2}$ & $\bar{\tau}_{\text {exp }}$ & & & & & \\
\hline 1 & 210 & 230 & 220 & 100 & 200 & 220 & 0 & 0 \\
\hline 2 & 440 & 460 & 450 & 100 & 200 & 449 & 1 & 1 \\
\hline 3 & 290 & 310 & 300 & 100 & 200 & 300 & 0 & 0 \\
\hline 4 & 340 & 360 & 350 & 100 & 200 & 350 & 0 & 0 \\
\hline 5 & 640 & 680 & 660 & 400 & 800 & 652 & 8 & 64 \\
\hline 6 & 1000 & 1040 & 1020 & 400 & 800 & 1004 & 16 & 256 \\
\hline 7 & 1080 & 1200 & 1140 & 3600 & 7200 & 1142 & -2 & 4 \\
\hline 8 & 1230 & 1390 & 1310 & 6400 & 12800 & 1314 & -4 & 16 \\
\hline$\sum$ & & & & & 22400 & & & 341 \\
\hline
\end{tabular}

In this work, we used the central compositional orthogonal planning of the second order (CCOP) followed by mathematical modeling in Maple software packages according to the author's algorithms.

As a result, we have obtained the regression coefficients, which are given in the bottom row of table. 6 . Thus, the regression equation in the coded quantities has the form:

$$
\begin{aligned}
& t=681,25+351,25 \cdot x_{1}+93,75 \cdot x_{2}+101,25 \cdot x_{3}+98,75 \cdot x_{1} \cdot x_{2}+31,25 \cdot x_{1} \cdot x_{3}- \\
& -46,25 \cdot x_{2} \cdot x_{3}-1,25 \cdot x_{1} \cdot x_{2} \cdot x_{3} .
\end{aligned}
$$

Full-sized equation has the form:

$$
\begin{aligned}
& \tau=-20,83+411,67 m_{o z}+6,17 t_{e x t}+1,08 \delta_{i n s}+13,67 m_{\mathrm{oz}} t_{e x t}+ \\
& +1,63 m_{o z} \delta_{i n s}-0,18 t_{e x t} \delta_{i n s}-0,0067 m_{o z} t_{e x t} \delta_{i n s} .
\end{aligned}
$$

According to the requirements of regression analysis, the variance of the matrix row must be homogeneous. Homogeneity of variances is checked by Cochran's $\mathrm{C}$ test:

$$
G=\frac{S_{j_{\max }}^{2}}{\sum_{j=1}^{N} S_{j}^{2}}
$$


where $S_{j_{\max }}^{2}$ the largest of the dispersions calculated as $S_{j}=\frac{\sum_{n=1}^{n}(-\bar{\tau}-\tau)^{2}}{k-1}$; $k$ - number of replicate observations (in this case 2).

$$
G=\frac{12800}{22400}=0,571 .
$$

The variance is considered homogeneous if the value of Cochran's $\mathrm{C}$ test calculated by the given equation satisfies the condition

$$
G<G_{\text {tabl }},
$$

where $G_{\text {tabl }}$ - tabulated value of Cochran's C test for a given $N$ and number of degrees of freedom $f$, moreover $f=k-1$. In our case $f=2-1=1$.

Tabulated value $G_{\mathrm{tabl}}$, which corresponds to confidence coefficient 0,95 , is equal to 0,6798 . As $G(0,571)<G_{\text {tabl }}(0,6798)$, the dispersion is homogeneous.

We calculated the error mean square to assess the significance of the regression coefficients:

$$
S_{y}^{2}=\frac{1}{N} \sum_{j=1}^{N} S_{j}^{2}=\frac{1}{8} 22400=2800
$$

and the error of their definition $S_{b}$

$$
S_{b}=\sqrt{\frac{S_{y}^{2}}{N k}}=\sqrt{\frac{2800}{8 \cdot 2}}=13,23 .
$$

The significance of the regression coefficients is established according to the error of their determination and Student's t-test $t_{p}$. If the condition $t_{p} \leq b / S_{b}$ is satisfied, the regression coefficient is significant. With a probability of $95 \%$ and $N=8 t_{p}=2,31$.

Determining the values of $b / S_{b}$ for the members of the equation and comparing the calculated value with the tabular value of Student's t-test [306] allowed us to discard the last number of the regression equation, which takes into account the combined effect on battery discharging time of ozokerite, external temperature and insulation layer thickness.

Thus, the regression equation has the form: 
in coded values

$$
\begin{aligned}
& t=681,25+351,25 \cdot x_{1}+93,75 \cdot x_{2}+101,25 \cdot x_{3}+ \\
& +98,75 \cdot x_{1} \cdot x_{2}+31,25 \cdot x_{1} \cdot x_{3}-46,25 \cdot x_{2} \cdot x_{3},
\end{aligned}
$$

in full-sized

$$
\begin{aligned}
& \tau=-20,83+411,67 m_{o z}+6,17 t_{e x t}+1,08 \delta_{i n s}+ \\
& +13,67 m_{\mathrm{oz}} t_{e x t}++1,63 m_{o z} \delta_{i n s}-0,18 t_{e x t} \delta_{i n s} .
\end{aligned}
$$

The adequacy of the experimental equation is checked by F-test. The variance of adequacy is calculated according to table. 3 of the ratio:

$$
S_{\text {ad }}^{2}=\frac{2}{N-B} \sum_{j=1}^{N}\left(\bar{\tau}-\tau_{\text {calc. }}\right)^{2}=\frac{2}{8-7} 341=682,
$$

where $B$ - the number of significant coefficients in the regression equation.

The calculated value of the $F$-ratio is calculated as the ratio of the variances of adequacy and reproducibility, and, in the numerator of the F-ratio put the largest of the variances. By this means:

$$
F=\frac{S_{y}^{2}}{S_{a d}^{2}}=\frac{2800}{682}=4,11 .
$$

If the value of F-test obtained by this ratio does not exceed the tabular value $\left(\mathrm{F}_{\text {tabl. }}\right)$ for a given number of degrees of freedom, the regression equation is adequate and the adequacy condition is $F \leq F_{\text {tabl. }}$. For $P=0,95, f_{1}=N-B=8-7=1$ and $f$ ${ }_{2}=N(k-1)=8(2-1)=8$ F-test is equal to 5,3 , that is $F<F_{\text {tabl. }}$ Therefore, the regression equation obtained by us is adequate to the experiment.

To test the possibility of using the obtained regression equation for any points lying between the upper and lower levels of variation, we performed the experiments to determine the discharging time HA under the conditions specified in table. 8 . 
Table 8

Checking the possibility of using the regression equation for arbitrary conditions

\begin{tabular}{|c|c|c|c|c|c|c|c|}
\hline \multirow{2}{*}{$\begin{array}{c}\text { Experi } \\
\text { ment } \\
\text { № }\end{array}$} & \multirow{2}{*}{ Factors } & \multirow{2}{*}{$\begin{array}{l}\text { Factor } \\
\text { score }\end{array}$} & \multicolumn{3}{|c|}{$\begin{array}{l}\text { Discharging time, } \\
\text { min }\end{array}$} & \multirow{2}{*}{$\tau_{\text {calc. }}$} & \multirow{2}{*}{$\begin{array}{c}\text { Measu } \\
\text { rement } \\
\text { error, } \\
\%\end{array}$} \\
\hline & & & $\tau_{\text {exp. } 1}$ & $\tau_{\text {exp. } 2}$ & $\bar{\tau}_{\text {exp }}$ & & \\
\hline \multirow[t]{3}{*}{1} & mass of ozokerite in $\mathrm{HA}, \mathrm{kg}$; & 1,25 & \multirow[t]{3}{*}{695} & \multirow[t]{3}{*}{672} & \multirow[t]{3}{*}{683} & \multirow[t]{3}{*}{679} & \multirow[t]{3}{*}{0,6} \\
\hline & outside temperature, ${ }^{\circ} \mathrm{C}$; & -5 & & & & & \\
\hline & $\begin{array}{l}\text { the thickness of the insulation layer, } \\
\mathrm{mm}\end{array}$ & 75 & & & & & \\
\hline \multirow[t]{3}{*}{2} & mass of ozokerite in $\mathrm{HA}, \mathrm{kg}$; & 0,875 & \multirow[t]{3}{*}{397} & \multirow[t]{3}{*}{425} & \multirow[t]{3}{*}{411} & \multirow[t]{3}{*}{410} & \multirow[t]{3}{*}{0,2} \\
\hline & outside temperature, ${ }^{\circ} \mathrm{C}$; & $-12,5$ & & & & & \\
\hline & $\begin{array}{l}\text { the thickness of the insulation layer, } \\
\mathrm{mm}\end{array}$ & 62,75 & & & & & \\
\hline \multirow[t]{3}{*}{3} & mass of ozokerite in $\mathrm{HA}, \mathrm{kg}$; & 1,625 & \multirow[t]{3}{*}{915} & \multirow[t]{3}{*}{953} & \multirow[t]{3}{*}{934} & \multirow[t]{3}{*}{943} & \multirow[t]{3}{*}{0,9} \\
\hline & outside temperature, ${ }^{\circ} \mathrm{C}$; & $-2,5$ & & & & & \\
\hline & $\begin{array}{l}\text { the thickness of the insulation layer, } \\
\mathrm{mm}\end{array}$ & 87,5 & & & & & \\
\hline \multirow[t]{3}{*}{4} & mass of ozokerite in $\mathrm{HA}, \mathrm{kg}$ & 2 & \multirow[t]{3}{*}{808} & \multirow[t]{3}{*}{842} & \multirow[t]{3}{*}{825} & \multirow[t]{3}{*}{828} & \multirow[t]{3}{*}{0,4} \\
\hline & outside temperature, ${ }^{\circ} \mathrm{C}$; & -15 & & & & & \\
\hline & $\begin{array}{l}\text { the thickness of the insulation layer, } \\
\mathrm{mm}\end{array}$ & 75 & & & & & \\
\hline
\end{tabular}

These data indicate the suitability of the regression equation for calculating the time of discharge of HA in the conditions limited to the table. 5 values of variable factors.

Since the HA is a device that has certain characteristics, such as the mass of ozokerite in it (determined by the size of the HA) and the thickness of the insulation, in real conditions, these values are constant. Factor experiment makes it possible to establish their optimal values, which are taken into account in the manufacture of heat accumulators for a particular car. Thus, for the conditions of experiment 4 (Table 8), the discharge of the HA occurs for almost 14 hours, i.e, at $-15{ }^{\circ} \mathrm{C}$ you can leave the car overnight, and then start the engine for 5-10 s. 
Based on the results of our research on design involving numerical simulation and modern software, data were obtained to determine the warm-up time of the engine with a heat accumulator and a model that can be used to select design parameters of heat accumulators, justify the applicability of heat storage and forecasting system operation in different conditions.

Experimental and industrial samples of heat accumulators were created and their work was studied. To describe the operation of the heat accumulator, a regression equation is obtained, which allows to determine the discharge time of the heat accumulator depending on external conditions and its design features. 